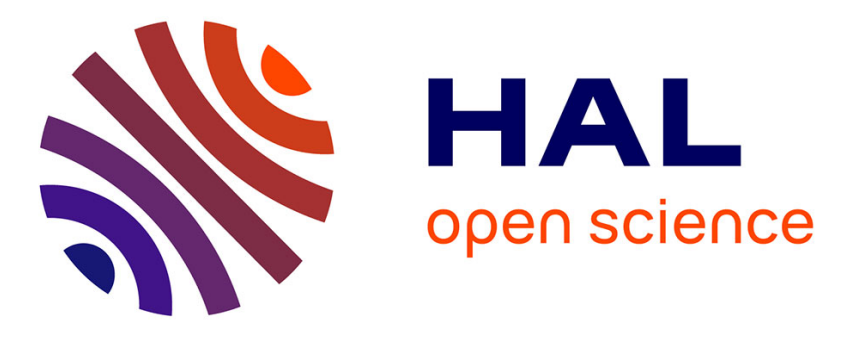

\title{
Probing the polarity of spontaneous perisomatic GABAergic synaptic transmission in the mouse CA3 circuit in vivo
}

Olivier Dubanet, Arnaldo Ferreira Gomes da Silva, Andreas Frick, Hajime Hirase, Anna Beyeler, Xavier Leinekugel

\section{To cite this version:}

Olivier Dubanet, Arnaldo Ferreira Gomes da Silva, Andreas Frick, Hajime Hirase, Anna Beyeler, et al.. Probing the polarity of spontaneous perisomatic GABAergic synaptic transmission in the mouse CA3 circuit in vivo. Cell Reports, 2021, 36 (2), pp.109381. 10.1016/j.celrep.2021.109381 . hal-03328694

\section{HAL Id: hal-03328694 \\ https://hal-amu.archives-ouvertes.fr/hal-03328694}

Submitted on 30 Aug 2021

HAL is a multi-disciplinary open access archive for the deposit and dissemination of scientific research documents, whether they are published or not. The documents may come from teaching and research institutions in France or abroad, or from public or private research centers.
L'archive ouverte pluridisciplinaire HAL, est destinée au dépôt et à la diffusion de documents scientifiques de niveau recherche, publiés ou non, émanant des établissements d'enseignement et de recherche français ou étrangers, des laboratoires publics ou privés.

\section{(ㅇ)(1) $\$$}

Distributed under a Creative Commons Attribution - NonCommercial - NoDerivatives 44.0 


\section{Cell Reports}

\section{Probing the polarity of spontaneous perisomatic GABAergic synaptic transmission in the mouse CA3 circuit in vivo}

\section{Graphical abstract}

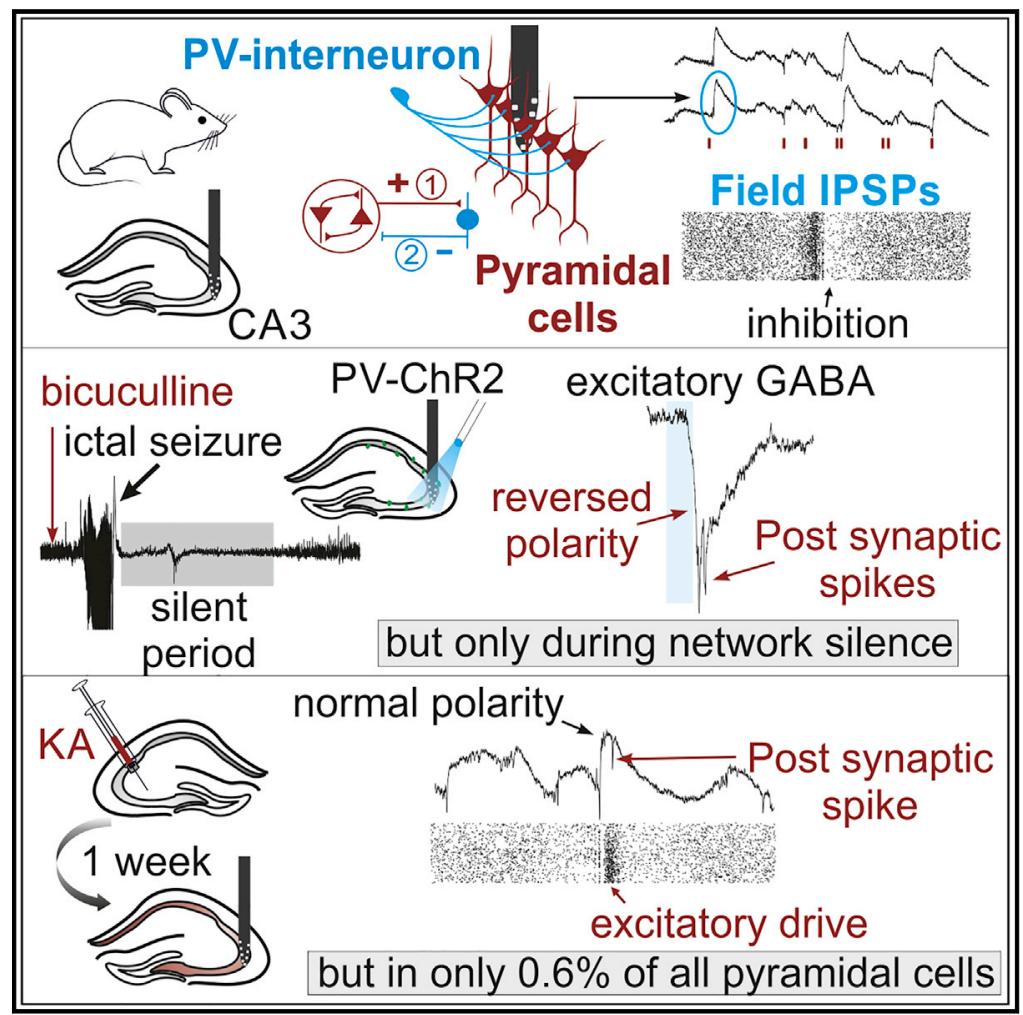

\section{Highlights}

- CA3 PV-interneurons generate perisomatic unitary GABAergic field potentials in vivo

- GABAergic unitary fields can be used to probe inhibition with single-cell resolution

- GABA reversal after acute seizures is restricted to the postictal silent period

- GABAergic excitation during KA epileptogenesis is restricted to $0.6 \%$ of $\mathrm{CA} 3$ neurons

\section{Authors}

Olivier Dubanet, Arnaldo Ferreira Gomes Da Silva, Andreas Frick, Hajime Hirase, Anna Beyeler, Xavier Leinekugel

\section{Correspondence}

xavier@arcadi.eu

\section{In brief}

Dubanet et al. show that extracellular probing of perisomatic GABAergic transmission in the mouse CA3 circuit in vivo does not support the hypothesis of excitatory GABA in epileptogenesis, but represents a promising tool for the direct assessment of GABAergic transmission in different pathological conditions that may affect the hippocampal circuit. 


\title{
Article
}

\section{Probing the polarity of spontaneous perisomatic GABAergic synaptic transmission in the mouse CA3 circuit in vivo}

\author{
Olivier Dubanet, ${ }^{1}$ Arnaldo Ferreira Gomes Da Silva, ${ }^{1,2}$ Andreas Frick, ${ }^{1}$ Hajime Hirase, ${ }^{3}$ Anna Beyeler, ${ }^{1}$ \\ and Xavier Leinekugel ${ }^{1,2,4, *}$ \\ 1 University of Bordeaux, INSERM U1215, Neurocentre Magendie, 33077 Bordeaux, France \\ 2INMED, INSERM, Aix Marseille Univ, France \\ ${ }^{3}$ Center for Translational Neuromedicine, University of Copenhagen, Copenhagen, Denmark \\ ${ }^{4}$ Lead contact \\ ${ }^{*}$ Correspondence: xavier@arcadi.eu \\ https://doi.org/10.1016/j.celrep.2021.109381
}

\section{SUMMARY}

The hypothesis that reversed, excitatory GABA may be involved in various brain pathologies, including epileptogenesis, is appealing but controversial because of the technical difficulty of probing endogenous GABAergic synaptic function in vivo. We overcome this challenge by non-invasive extracellular recording of neuronal firing responses to optogenetically evoked and spontaneously occurring inhibitory perisomatic GABAergic field potentials, generated by individual parvalbumin interneurons on their target pyramidal cells. Our direct probing of GABAergic transmission suggests a rather anecdotal participation of excitatory GABA in two specific models of epileptogenesis in the mouse CA3 circuit in vivo, even though this does not preclude its expression in other brain areas or pathological conditions. Our approach allows the detection of distinct alterations of inhibition during spontaneous activity in vivo, with high sensitivity. It represents a promising tool for the investigation of excitatory GABA in different pathological conditions that may affect the hippocampal circuit.

\section{INTRODUCTION}

Fast and time-locked inhibition, considered essential for network balance and neuronal coding, is mediated by $\mathrm{GABA}_{A}$ receptors $\left(G_{A B A_{A}} R\right)$, which are permeable to chloride ions $\left(\mathrm{Cl}^{-}\right)$. In normal conditions, neurons maintain a low intracellular concentration of chloride $\left(\left[\mathrm{Cl}^{-}\right] \mathrm{i}\right)$, so that the reversal potential of $\mathrm{Cl}^{-}$-mediated currents is more negative than the resting potential (Blaesse et al., 2009). GABA release therefore generates an influx of $\mathrm{Cl}^{-}$, with a hyperpolarizing effect on membrane potential, and an inhibition of neuronal discharge.

Recent publications have proposed the implication of defective inhibition in the etiology of various pathologies, including epilepsy, depression, schizophrenia, Down syndrome, or autism spectrum disorders (Menendez de la Prida and Trevelyan, 2011; Cellot and Cherubini, 2014; Tyzio et al., 2014; Deidda et al., 2015; Doyon et al., 2016; Lopez-Pigozzi et al., 2016; Ben-Ari, 2017; Valero et al., 2017; Kharod et al., 2019). In vitro and in vivo experiments have suggested that the defective function of the $\mathrm{K}-\mathrm{Cl}$ co-transporter $\mathrm{KCC} 2$, which would normally extrude $\mathrm{Cl}^{-}$from the cell, was responsible for a reversed polarity of GABAergic transmission from inhibitory to excitatory, participating in epileptogenesis in animal models (Khalilov et al., 2003; Pathak et al., 2007; Riekki et al., 2008; Bragin et al., 2009; Barmashenko et al., 2011; Nardou et al., 2011; Ellender et al.,
2014; Chen et al., 2017; Moore et al., 2017; Wang et al., 2017; Di Cristo et al., 2018; Magloire et al., 2019), as well as in human tissue resected from patients with epilepsy (Cohen et al., 2002; Huberfeld et al., 2007; Pallud et al., 2014). One major difficulty in the study of GABAergic inhibition is to avoid artifactual interference with the native $\mathrm{Cl}^{-}$gradient, a main determinant of $\mathrm{GABA}_{A}$ $R$-mediated inhibitory function. Perforated-patch clamp recordings with the compound antibiotic gramicidin provide electrical access to the cell through the formation of pores in the membrane, permeable to cations but impermeant to $\mathrm{Cl}^{-}$. Perforated-patch recordings with gramicidin have been successfully used in vitro to record GABAergic synaptic currents, preserving intracellular $\mathrm{Cl}^{-}$(Gulledge and Stuart, 2003; Khalilov et al., 2003; Pathak et al., 2007; Barmashenko et al., 2011; Ellender et al., 2014). The $\mathrm{Cl}^{-}$gradient has also been shown to be affected by the slicing procedure (van den Pol et al., 1996; Dzhala et al., 2012; Valeeva et al., 2016), which calls into question the claims for excitatory GABAergic transmission based on in vitro recordings (Valeeva et al., 2016).

In vivo treatment with the diuretic bumetanide, which also reduces the accumulation of $\mathrm{Cl}^{-}$ions in neurons through the inhibition of the $\mathrm{Cl}^{-}$intruder NKCC1, was found to reduce behavioral abnormalities in rat and mouse models of autism spectrum disorders (Tyzio et al., 2014) and seizures in animal models of epilepsy (Dzhala et al., 2005; Kahle and Staley, 2008; Brandt 
et al., 2010; Marguet et al., 2015; Kourdougli et al., 2017; Wang et al., 2017). Bumetanide, however, has a limited bioavailability in the brain due to poor blood-brain barrier penetration (Puskarjov et al., 2014; Donovan et al., 2016; Römermann et al., 2017), and it is unclear whether its action in vivo was actually due to the restoration of neuronal $\mathrm{Cl}^{-}$gradient and inhibitory GABAergic transmission.

Direct investigation of the polarity of GABAergic transmission in vivo puts serious constraints in terms of experimental access, and the evaluation of responses to spontaneous synaptic $G A B A_{A} R$ activation is challenging. The ideal method would fully preserve the exact spatiotemporal interactions between membrane potential, conductance, and ongoing synaptic inputs (both excitatory and inhibitory), the natural dynamics of which are highly complex and yet critical for the net inhibitory or excitatory effect of GABAergic transmission (Lu and Trussell, 2001; Gulledge and Stuart, 2003; Lovett-Barron et al., 2012; Astorga et al., 2015; Assaf and Schiller, 2016; Magloire et al., 2019). Adapting to in vivo conditions the extracellular recording of GABAergic postsynaptic potentials (field inhibitory postsynaptic potential [IPSPs]) previously described in vitro (Glickfeld et al., 2009; Bazelot et al., 2010; Beyeler et al., 2013), we were able to evaluate the polarity of perisomatic GABAergic signaling during spontaneous activity in the intact brain.

\section{RESULTS}

Extracellular recording of perisomatic field IPSPs and time-locked inhibition of CA3 pyramidal cell firing in vivo Non-invasive recording of the dynamics of GABAergic synaptic transmission in vivo is a challenge. Previous work in vitro has suggested that perisomatic inhibitory postsynaptic signals originating from individual interneurons (basket and chandelier cells) could be recorded as extracellular field potentials (field-inhibitory postsynaptic potentials [fIPSPs]) from their target pyramidal cell population (Glickfeld et al., 2009; Bazelot et al., 2010; Beyeler et al., 2013). This approach offers several main advantages. First, extracellular recordings preserve native $\left[\mathrm{Cl}^{-}\right] \mathrm{i}$ and other cytoplasmic factors critical for GABAergic transmission (Glykys et al., 2014). Second, the polarity of the field events indicates the direction of the current elicited in the target population of pyramidal cells, thereby addressing the question of depolarizing versus hyperpolarizing polarity of GABAergic postsynaptic signaling. Third, combined with unit recording and spike sorting of neuronal discharges, the extracellular detection of population fIPSPs provides a time reference to investigate the net effect of GABAergic perisomatic synaptic signals on the firing of the target neurons with single-cell resolution, allowing a direct quantification of the efficacy of inhibition or excitation provided by perisomatic GABAergic inputs. To evaluate the efficiency and polarity of perisomatic GABAergic transmission in the hippocampus in vivo, we have therefore inserted silicon probes into the dorsal CA3 pyramidal layer of urethane-anesthetized mice, recording spontaneous local field potentials and unitary neuronal activity.

Basic properties of spontaneous fIPSPs

As illustrated in Figure 1, spontaneous activity from the CA3 pyramidal layer included action potentials (APs, units) and positive local field events with a profile similar to that of fIPSPs previously described in vitro as the $\mathrm{GABA}_{\mathrm{A}}$ receptor-mediated postsynaptic potentials originating from parvalbumin (PV) interneurons (Beyeler et al., 2013). Accordingly, these events were characterized by a rapid rise time and a slow decay (time to peak, $2.01 \pm$ $0.53 \mathrm{~ms}$, exponential decay time constant, $3.65 \pm 0.05 \mathrm{~ms}, \mathrm{n}=$ 8 mice), and showed the pharmacological profile of $G_{A B A} R-$ mediated IPSPs. As illustrated in Figure S1B, fIPSPs persisted (although with reduced frequency) in the presence of locally injected glutamatergic antagonists (frequency of occurrence, $16.3 \% \pm 5.6 \%$ of control in D-(-)-2-amino-5-phosphonopentanoate+6,7-dinitroquinoxaline-2,3-dione (APV+DNQX), 5 and $2 \mathrm{mM}$, respectively, $200-300 \mathrm{~nL}$ ), at a dose that efficiently abolished glutamatergic transmission, as indicated by the loss of the local field potential (LFP) response evoked by the contralateral electrical stimulation of CA3 inputs. In contrast, fIPSPs were fully blocked by the $\mathrm{GABA}_{\mathrm{A}} \mathrm{R}$ antagonist bicuculline ( $0 \%$ of control in presence of bicuculline $100 \mu \mathrm{M}, 200 \mathrm{~nL}$, with or without APV+DNQX, $n=3$ mice, 1-way ANOVA, $F(3)=872.37, p<$ $0.001)$. The decay kinetics of fIPSPs were prolonged by the $\mathrm{GABA}_{\mathrm{A}}$ modulators diazepam (2 mg/kg, intraperitoneal [i.p.]) and zolpidem (10 $\mathrm{mg} / \mathrm{kg}$, i.p.). Because fIPSPs amplitude is directly affected by resting membrane potential, an uncontrolled parameter in our extracellular recording conditions, we have restricted our analysis to the decay kinetics of fIPSPS. As illustrated in Figure $1 \mathrm{C}$, zolpidem increased the spontaneous fIPSPs decay time constant by $\sim 180 \%$ (from $4.66 \pm 0.36$ to $13.07 \pm$ $4.18 \mathrm{~ms}, \mathrm{n}=5$ mice, $\mathrm{p}<0.01$, 2-tailed paired t test, $\mathrm{t}(4)=$ -4.62 ), and diazepam by $\sim 15 \%$ (from $3.65 \pm 0.05$ to $4.19 \pm$ $0.06 \mathrm{~ms}, \mathrm{n}=3$ mice, $\mathrm{p}<0.01$, 2-tailed paired t test, $\mathrm{t}(2)=9.13$ ). Time-locked inhibition of pyramidal cells

As observed in vitro and expected from perisomatically projecting interneurons (basket and chandelier cells), in vivo fIPSPs were associated with the time-locked inhibition of local pyramidal cells. As shown in Figure 1, beside the peak firing that precedes fIPSPs and probably reflects the recruitment of perisomatic inhibition by pyramidal cell discharge (Beyeler et al., 2013), most of the 389 putative pyramidal cells obtained from 18 mice were significantly inhibited after fIPSPs $(71.1 \% \pm$ $12.9 \%$ of the neurons tested, $\mathrm{n}=18 \mathrm{mice}$ ), resulting in a population firing reduced by $83.5 \% \pm 10.4 \%$, returning to baseline values after $10.2 \pm 3.5 \mathrm{~ms}(\mathrm{n}=18$ mice).

\section{Perisomatic fIPSPs specifically originate from PV} interneurons

\section{Optogenetic activation of PV interneurons}

To verify that fIPSPs actually originate from PV interneurons, we recorded the extracellular field potential responses to the optogenetic activation of PV interneurons. PV-Cre mice were injected with the DIO hChR2 (E123T/T159C)-EYFP (double-floxed inverse open reading frame-human channelrhodopsin 2 (E123T/ T159C)-enhanced yellow fluorescent protein) construct in the CA3 region to express the cationic actuator ChR2 specifically in PV interneurons. PV immunostaining of the infected mice showed excellent specificity, with $96 \%$ to $100 \%(98.3 \% \pm 2 \%$, $\mathrm{n}=3$ mice) of the infected $\left(\mathrm{GFP}^{+}\right)$cells being also $\mathrm{PV}^{+}$(Figure S1A). As illustrated in Figures 2 and S2, brief (2 ms) local optogenetic activation of PV interneurons evoked fIPSPs, together 

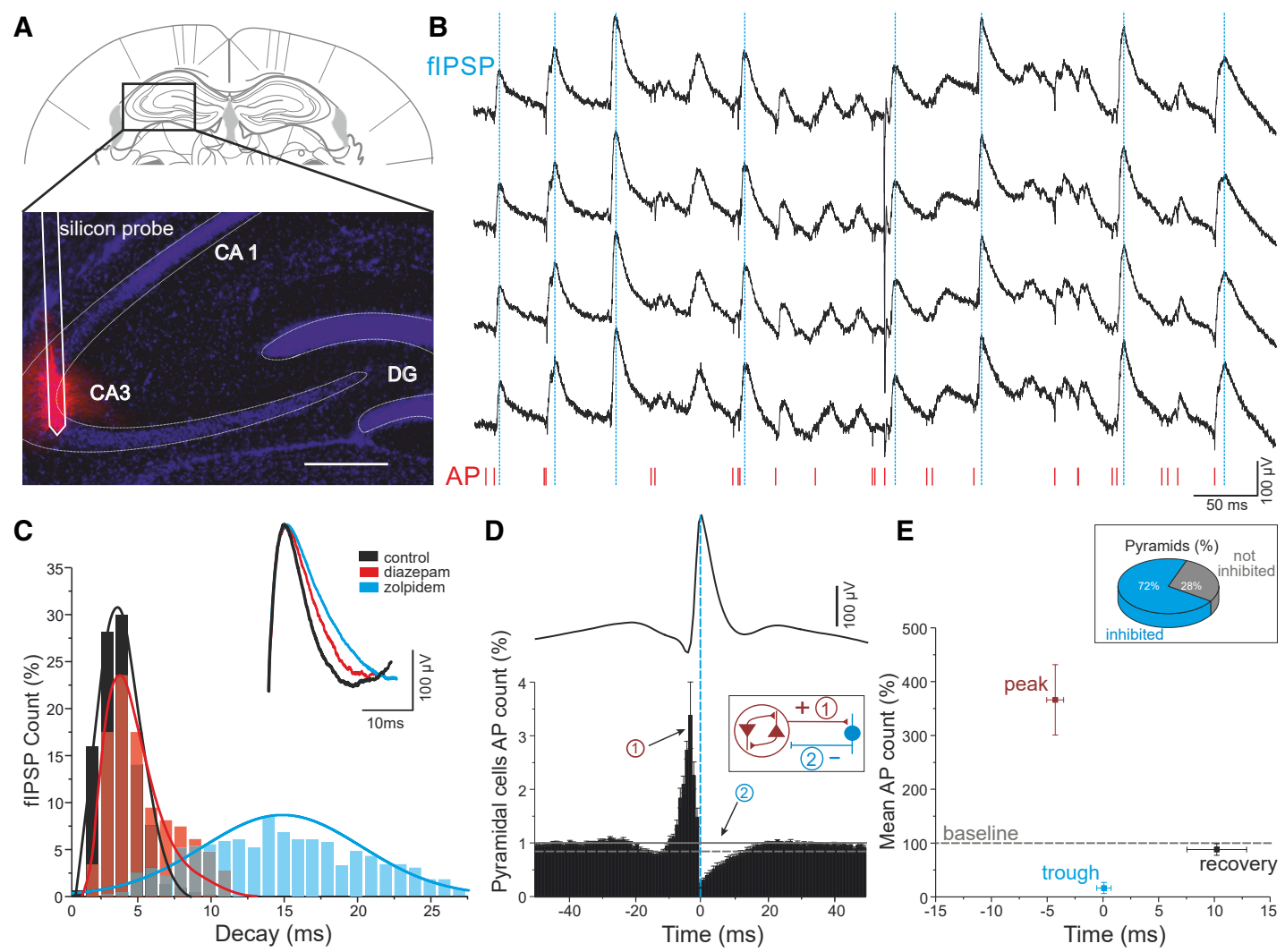

$\mathbf{E}$
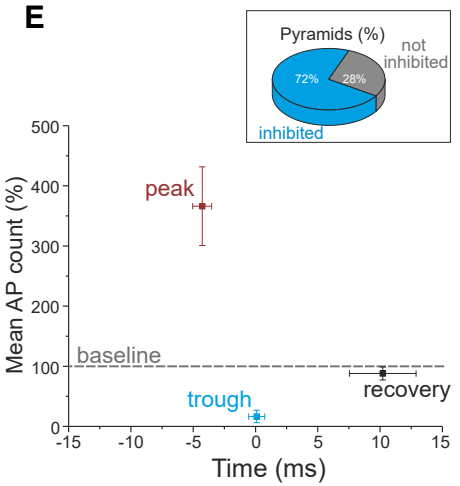

Figure 1. Spontaneous extracellular field inhibitory postsynaptic potentials (fIPSPs) in vivo

(A) Schematic of electrode track and histological verification of recording location within the CA3 hippocampal region (1,1-dioctadecyl-3,3,3,3-tetramethylindocarbocyanine perchlorate [Dil]-labeled silicon probe in red, DAPI staining in blue). Scale bar, $100 \mu \mathrm{m}$.

(B) Example trace of spontaneous wide-band $(0.1 \mathrm{~Hz}-9 \mathrm{KHz})$ field-recording activity in the CA3 pyramidal layer, displaying 4 channels (10-20 $\mu \mathrm{m}$ distance between recording sites) of the same shank of a 2-shanks Neuronexus Buzsaki16 silicon probe (scale bars, $50 \mathrm{~ms}, 100 \mu \mathrm{V}$ ). Field events of positive polarity (upward deflections), fIPSPs (peaks, dashed blue lines). Fast downward deflections, action potentials (AP), also labeled below as raster display (red ticks, multiunit activity). Note the transient interruption of neuronal firing after fIPSPs.

(C) Comparison of fIPSP decay (top, superimposed average traces normalized on amplitude; below, histogram distributions of fIPSPs decay times) in control (black, $n=934$ events from 8 mice), in the presence of zolpidem (blue, $n=566$ events from 5 mice) or diazepam (red, $n=259$ events from 3 mice). Note prolonged fIPSP decay in the presence of zolpidem and diazepam.

(D) Peri-event time histogram (mean $\pm \mathrm{SD}, \mathrm{n}=18 \mathrm{WT}$ mice, time bin $1 \mathrm{~ms}$ ) between all the spikes discharged by putative pyramidal cells and flPSPs (reference, peak time), shown as average trace (vertical scale bar, $100 \mu \mathrm{V}$ ) on top at the same timescale and aligned on peak (dotted blue line). Baseline mean and $2 \mathrm{SD}$ are shown as plain and dotted horizontal gray lines, respectively. Note increased pyramidal cell discharge in the $10 \mathrm{~ms}$ before fIPSP, and the inhibition (trough, maximum inhibition) that follows. Inset, schematic illustration of the recurrent excitatory/inhibitory loop: (1) the collective discharge of interconnected pyramidal cells activates the discharge of local interneurons, resulting (2) in perisomatic fIPSP and inhibition of pyramidal population activity.

(E) Diagram illustrating firing rates (mean \pm SEM, same 18 mice as in $\mathrm{D}$; baseline level $=100 \%$, calculated from -50 to -30 ms) at peak (bin of maximum firing in the $10 \mathrm{~ms}$ before fIPSPs), trough (bin of minimum firing in the 4-ms post-fIPSPs), and recovery (last of post-fIPSPs time bin below baseline - 2SD) time points. Inset, proportion of pyramidal cells ( $\mathrm{n}=18$ mice, for a total of 389 cells) with a significant post-fIPSPs trough (i.e., inhibited versus non-inhibited neurons).

with time-locked inhibition of local pyramidal cells ( $n=33$ pyramidal cells from 5 mice). Compared to spontaneous fIPSPs, evoked fIPSPs ( $n=5$ mice) had a longer decay time constant $(5.45 \pm 1.15 \mathrm{~ms}$ for evoked versus $4.11 \pm 0.73 \mathrm{~ms}$ for spontaneous, $\mathrm{t}(4)=2.93, \mathrm{p}<0.05)$, faster rise time $(1.54 \pm 0.15$ versus $1.96 \pm 0.15 \mathrm{~ms}, \mathrm{t}(4)=-3.38, \mathrm{p}<0.01)$, and larger amplitude $(287.5 \pm 40.53 \mu \mathrm{V}$ versus $218.1 \pm 15.48 \mu \mathrm{V}, \mathrm{t}(4)=-3.19, \mathrm{p}<$ $0.05)$. As illustrated in Figures $2 \mathrm{G}-2 \mathrm{I}$, the success rate of $P V$ interneuron optogenetic stimulation to evoke fIPSPs was not significantly affected by the local presence of the glutamatergic receptor antagonists APV and DNQX, but evoked fIPSPs were fully (and reversibly) blocked by the $\mathrm{GABA}_{A} \mathrm{R}$ antagonist bicuculline (success rate $81.5 \% \pm 7.1 \%$ in control, $91 \% \pm 11.6 \%$ in APV+DNQX, $0 \%$ in bicuculline, with or without APV+DNQX, 1-way ANOVA, $F(3)=162.15)$. $P V$ interneuron firing is therefore sufficient to evoke fIPSPs.

Chemogenetic silencing of PV interneurons

To know whether other types of interneurons also significantly contributed to the generation of perisomatic fIPSPs during spontaneous CA3 activity, PV-Cre mice were injected with the FLEXrev::PSAML141F,Y115F:GlyR-IRES-GFP construct to express the inhibitory chemogenetic pharmacologically selective actuator module-glycine receptor (PSAM-GlyR) specifically in PV interneurons. PV immunostaining of the infected mice showed that 
A
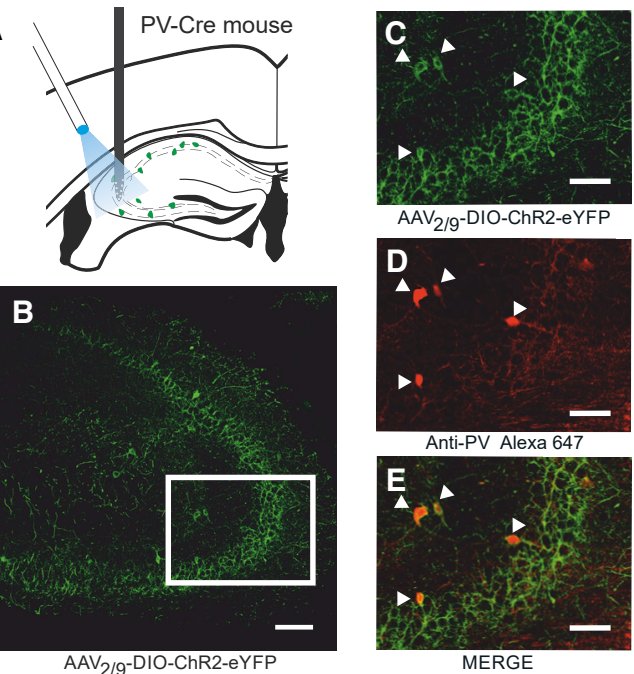

G

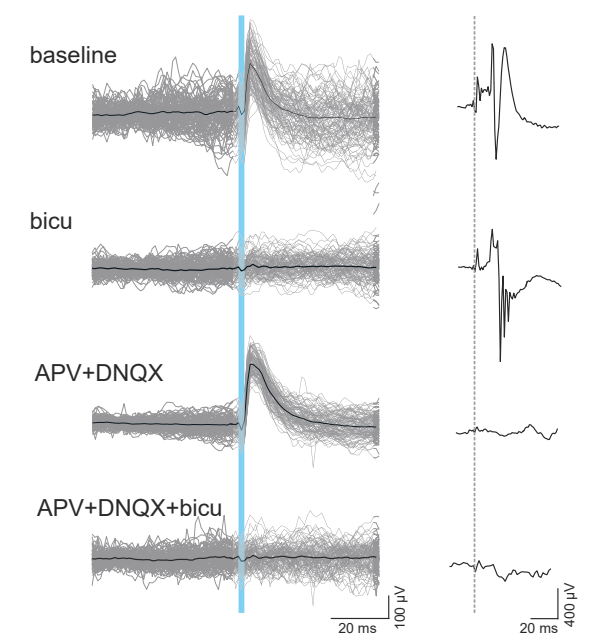

$\mathbf{F}$

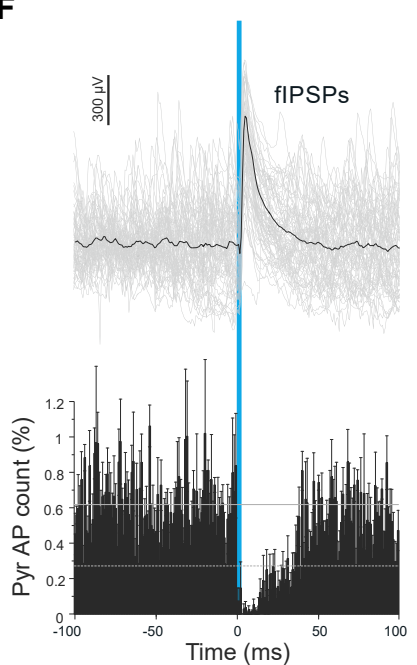

H

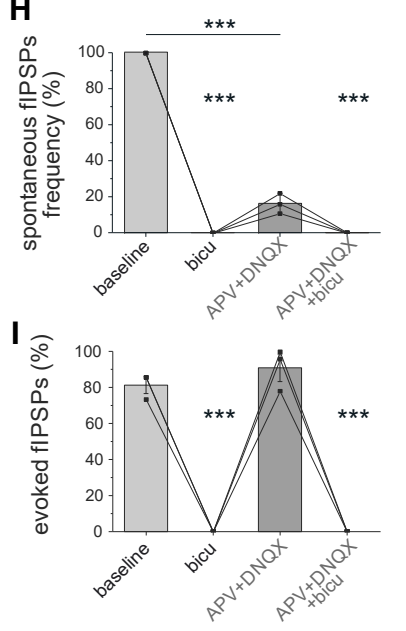

Figure 2. In vivo fIPSPs generated by optogenetic activation of PV interneurons

(A) Schematic representation of electrode and optical fiber positions in PV-Cre mice with AAV-driven ChR2 and EYFP expression in CA3 PV interneurons. (B-E) Confocal stacks of EYFP ${ }^{+}$(green) and $\mathrm{PV}^{+}$(red) immunostaining in the hippocampal CA3 region. (B) EYFP immunostaining (scale bar, $100 \mu \mathrm{m}$ ). (C-E) Higher magnification (scale bar, $5 \mu \mathrm{m}$ ) of the $\mathrm{CA}$ a region delimited by the white rectangle in (B). (C) EYFP immunostaining. (D) PV immunostaining. (E) Overlay. Note the co-localization on the 4 identified PV interneurons (arrowheads).

(F) Peri-event time histogram (mean \pm SEM, $\mathrm{n}=5$ mice, time bin $1 \mathrm{~ms}$ ) between all the spikes discharged by putative pyramidal cells and optogenetically evoked (laser ON 2 ms, blue bar) fIPSPs (reference), shown as superimposed (gray) and average (black) traces $(n=60$ from a single representative recording) on top, aligned and at the same timescale (vertical scale bar, $300 \mu \mathrm{V}$ ). Note the powerful time-locked inhibition of pyramidal cell firing in response to fIPSPs evoked by the optogenetic stimulation of PV interneurons.

(G) Example traces of fIPSPs (left, gray, superimposed, black, average; scale bars, $20 \mathrm{~ms}$ and $100 \mu \mathrm{V}$ ) evoked by the optogenetic stimulation of PV interneurons (vertical blue line, laser $\mathrm{ON}$ ), and of the LFP response evoked on the same recording electrode by the electrical stimulation of the contralateral CA3 region (right, scale bars, $20 \mathrm{~ms}, 400 \mu \mathrm{V}$ ). Note that the GABA $A_{A}$ antagonist bicuculline (bicu) blocked evoked fIPSPs and increased the electrically induced population response to multiple spikes, while the glutamatergic antagonists APV and DNQX abolished the electrically induced population response but not the evoked fIPSPs.

( $\mathrm{H}$ and $\mathrm{l}$ ) Summary plots (mean $\pm \mathrm{SD}, \mathrm{n}=3$ mice) of the effects of bicuculline, APV, and DNQX on the frequency of occurrence of spontaneous fIPSPs $(H)$, normalized to baseline frequency and on the success rate of evoking fIPSPs by the optogenetic stimulation of $P V$ interneurons (I). ${ }^{\star \star *} p<0.001$.

See also Figures $\mathrm{S} 1$ and $\mathrm{S} 2$. in addition to high specificity $(99 \% \pm 1 \%, \mathrm{n}=3$ mice), $98 \% \pm 1 \%$ $\left(\mathrm{n}=3\right.$ mice) of the $\mathrm{PV}^{+}$cells in the region of recording were also $\mathrm{GFP}^{+}$(Figure S1B), indicating that most PV interneurons expressed PSAM-GlyR. As illustrated in Figure 3, the chemogenetic inhibition of PV interneurons induced by local injection of the exogenous ligand PSEM-89S suppressed $92.6 \% \pm 9.7 \%$ (median $=97 \%, n=5$ mice) of spontaneous fIPSPs, from 6.58 \pm 3.5 to $0.45 \pm 0.66$ events $/ \mathrm{s}(n=5$ mice, $p<0.05,2$-sided Wilcoxon-Mann-Whitney test), suggesting that the recorded fIPSPs originated predominantly from PV interneurons. Chemogenetic silencing of $P V$ interneurons in the anesthetized mouse did, however, not increase the global firing rate of the CA3 pyramidal cell population (Figures $3 \mathrm{H} ; 1.19 \pm 2.72 \mathrm{~Hz}$ in control versus $0.96 \pm$ $1.04 \mathrm{~Hz}$ in PSEM-89S, $\mathrm{n}=5$ mice, not significant [NS], 2-sided Wilcoxon-Mann-Whitney test; 1-way ANOVA, $F(1)=1.51$, NS). The application of PSEM-89S in PV-Cre mice not injected with the PSAM-GlyR viral construct did not affect global hippocampal activity (average global pyramidal firing rate, $0.6 \pm 0.21 \mathrm{~Hz}$ in control versus $0.59 \pm 0.18 \mathrm{~Hz}$ with PSEM-89S; fIPSP frequency of occurrence, $6.72 \pm 1.71 \mathrm{~Hz}$ in control versus $6.31 \pm 1.44 \mathrm{~Hz}$ with PSEM-89S, $\mathrm{n}=5$ mice, Wilcoxon-Mann-Whitney ranksum test, NS).

\section{Depolarizing and excitatory perisomatic GABAergic} transmission in acute seizures in the drug-free mouse The reversal potential of $\mathrm{Cl}^{-}$-mediated GABAergic currents (EGABA) is controlled by the passive movement and active transport of $\mathrm{Cl}^{-}$through various ionic channels and transporters in the plasma membrane to reach the homeostatic set point for [Cl]i determined by local impermeant anions (Glykys et al., 2014). During spontaneous activity, $\mathrm{Cl}^{-}$ions flowing through $\mathrm{GABA}_{\mathrm{A}}$ channels tend to shift the reversal potential of GABAergic currents toward membrane potential. Changes in external $\left[\mathrm{K}^{+}\right]$will also affect the $\mathrm{K}-\mathrm{Cl}$ cotransport and $\mathrm{Cl}^{-}$gradient. E-GABA is therefore a very dynamic process that depends on ongoing fluctuations of membrane potential, GABAergic 

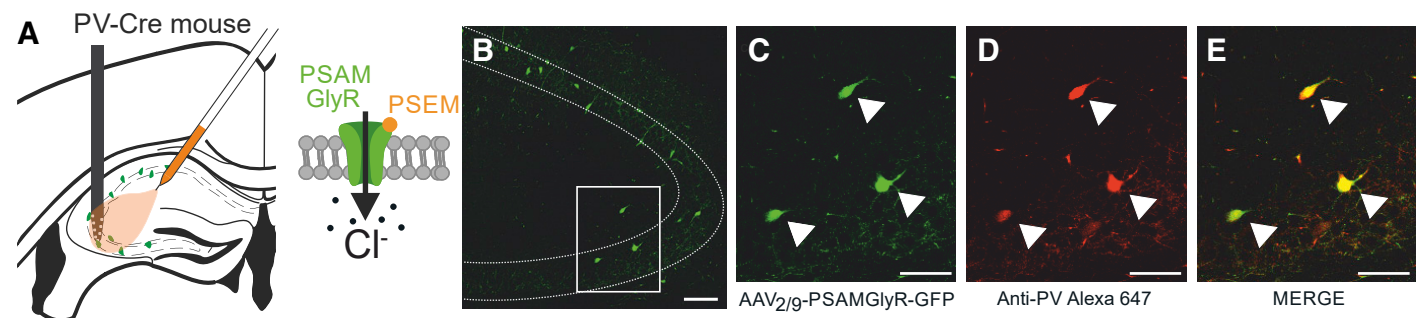

F Baseline

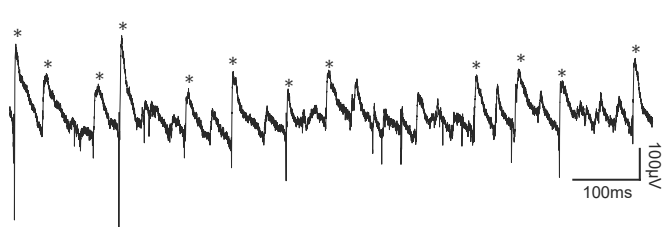

G

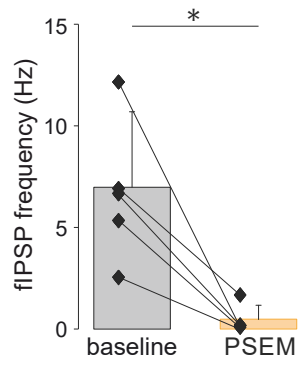

H

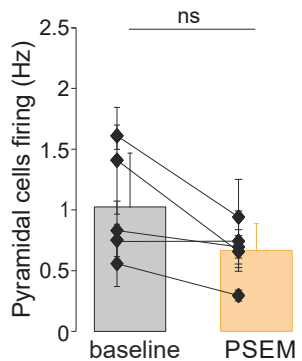

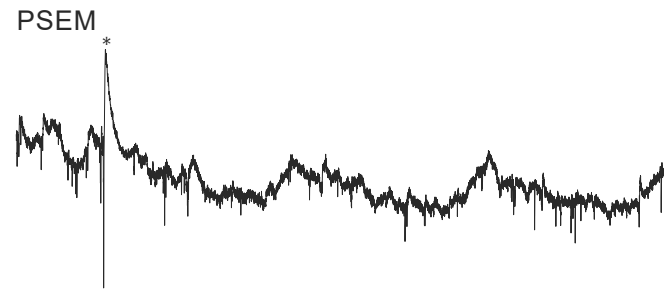

I

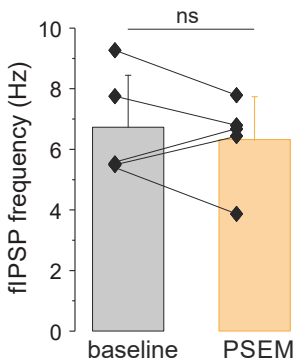

$\mathbf{J}$

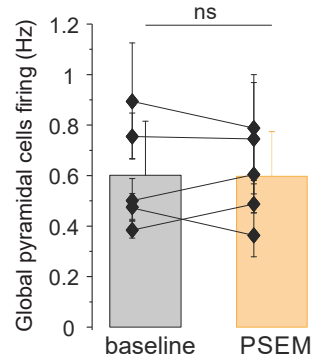

Figure 3. Inhibition of fIPSPs by chemogenetic inactivation of PV interneurons

(A) Schematic representation of electrode and injection site in PV-Cre mice with AAV-driven PSAM-GlyR and GFP expression in CA3 PV interneurons.

(B-E) Confocal stacks of GFP ${ }^{+}$(green) and $\mathrm{PV}^{+}$(red) immunostaining in the hippocampal CA3 region (see also Figure S1).

(B) GFP immunostaining (scale bar, $100 \mu \mathrm{m}$ ).

(C-E) Higher magnification (scale bar, $50 \mu \mathrm{m}$ ) of the CA3a region delimited by the white rectangle in (B).

(C) GFP immunostaining.

(D) PV immunostaining.

(E) Overlay. Note the co-localization of PV and PSAM-GlyR immunostaining on the 3 labeled interneurons (arrowheads).

(F) Example trace of spontaneous wide-band $(0.1 \mathrm{~Hz}-9 \mathrm{KHz})$ field-recording activity in the CA3 pyramidal layer (scale bars, $100 \mathrm{~ms}, 100 \mu \mathrm{V})$, in control (left, baseline) and in the presence of the exogenous ligand PSEM-89S (right, PSEM). Note the drastic reduction in fIPSPs expression (*).

$(\mathrm{G}$ and $\mathrm{H}$ ) Summary plots (mean $\pm \mathrm{SD}, \mathrm{n}=5$ mice) of fIPSP frequency $(\mathrm{G})$ and pyramidal population firing rate $(\mathrm{H})$ in control $(\mathrm{baseline})$ and in the presence of $\mathrm{PSEM}$ $\left({ }^{*} \mathrm{p}<0.05\right)$.

(I and J) Summary plots (mean \pm SD, $n=5$ mice) of fIPSP frequency (I) and pyramidal population firing rate (J) in control (baseline) and in the presence of PSEM$89 \mathrm{~S}$ in WT mice (i.e., not expressing PSAM-GlyR).

conductances, and network activity. During seizures, GABA is massively released by interneurons while pyramidal cells are depolarized and therefore loaded with $\mathrm{Cl}^{-}$until extrusion mechanisms restore a hyperpolarizing $\mathrm{Cl}^{-}$gradient. It is expected that due to the time course of $\mathrm{Cl}^{-}$extrusion, high $\mathrm{Cl}^{-}$load and excitatory GABA may participate in a deficit of inhibition immediately after a seizure (Fujiwara-Tsukamoto et al., 2003; Ellender et al., 2014). However, the time dynamics of spontaneous GABAergic synaptic transmission and the $\mathrm{Cl}^{-}$gradient through the interactions between the fluctuations of membrane potential and intrusion and extrusion systems, which have been studied in vitro, largely remain to be characterized in vivo. As illustrated in Figure 4, taking advantage of fIPSPs as a non-invasive index of the polarity of GABAergic currents in the CA3 pyramidal population, we have investigated the dynamics of perisomatic inhibition dur- ing acute interictal and ictal seizures in awake mice. Spontaneous fIPSPs in the head-fixed condition had a lower frequency of occurrence than under urethane anesthesia $(4.13 \pm 1.30 \mathrm{~Hz}$ versus $8.57 \pm 2.05, \mathrm{t}(8)=3.63, \mathrm{p}<0.01$ ) but comparable rise times $(1.81 \pm 0.23$ versus $1.956 \pm 0.15 \mathrm{~ms}, \mathrm{t}(8)=1.03, \mathrm{NS})$, decay time constants ( $3.65 \pm 0.45$ versus $4.11 \pm 0.73 \mathrm{~ms}, t(8)=1.04$, NS), and amplitudes $(206.4 \pm 9.35$ versus $218.1 \pm 15.48 \mu \mathrm{V}, \mathrm{t}(8)=-0.35$, NS).

\section{Reversed fIPSPs after acute seizures}

To monitor both spontaneous and evoked fIPSPs, PV-Cre mice were infected with the DIO-hChR2-EYFP construct in the CA3 region. Light stimulation with a locally positioned optical fiber evoked fIPSPs by the direct stimulation of PV interneurons. Acute seizures were induced by a brief and focal intra-hippocampal injection of the pro-epileptic agent bicuculline in the 
A

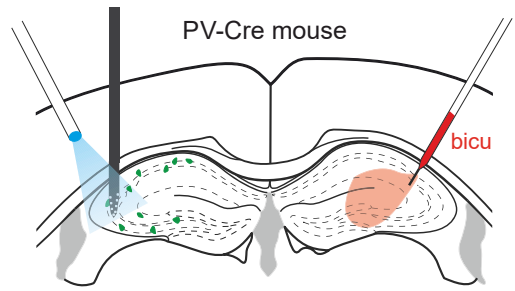

B

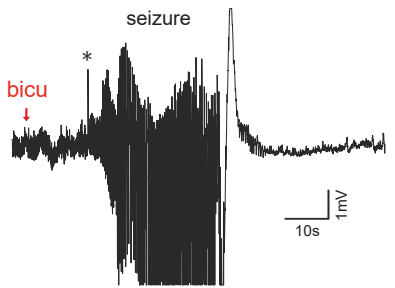

C ${ }^{800} 7$ pre-seizure

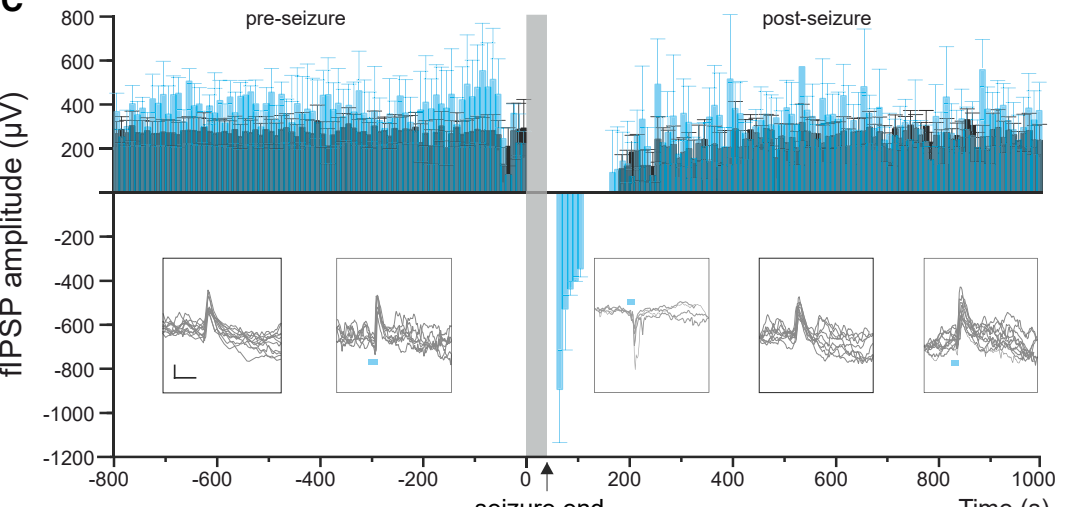

D

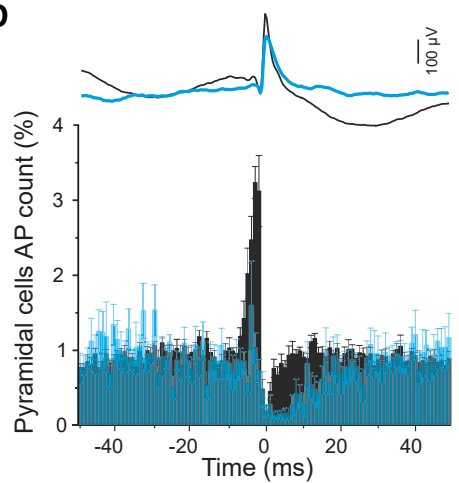

E

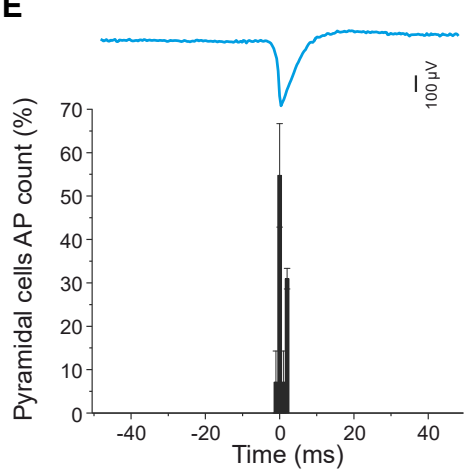

Figure 4. Transiently reversed fIPSPs and perisomatic GABAergic synaptic transmission following acute seizures

(A) Schematic representation of electrode and optical fiber positions in the left hippocampus of PV-Cre mice with AAV-driven ChR2 expression in CA3 PV interneurons, and contralateral injection of the proepileptic agent bicuculline.

(B) Example trace (wide-band LFP; scale bars, $10 \mathrm{~s}$, $1 \mathrm{mV}$ ) of a seizure (preceded by a single interictal spike, *) as acute response to contralateral bicuculline injection (red arrow).

(C) Summary plot of the time course of fIPSPs amplitude (mean \pm SEM, $\mathrm{n}=7$ mice, black bars, spontaneous; blue bars, evoked by optogenetic activation of PV interneurons; stimulation 2 ms every $2 \mathrm{~s}$ without interruption throughout the recording), relative to acute seizures induced by the contralateral injection of bicuculline (vertical gray bar, $\mathrm{n}=7$ mice, for a total of 14 seizures, aligned by their ending time). Insets, superimposed representative individual spontaneous (scale bars, $10 \mathrm{~ms}, 100 \mu \mathrm{V}$ ) and optogenetically evoked (horizontal blue bars, laser ON) fIPSPs in control (pre-seizure), during the period right after the seizure (reversed polarity), and after recovery (post-seizure). Note the progressive recovery of fIPSP amplitude. The absence of blue bars during and immediately after the seizure indicates the failures of optogenetically evoked response. See also Figure S3.

(D) Peri-event time histogram (mean $\pm \mathrm{SEM}$, time bin $1 \mathrm{~ms}$ ) between all the spikes discharged by putative pyramidal cells ( $\mathrm{n}=7$ mice) and spontaneous (in black, $n=44,435$ events) or optogenetically evoked (in blue, $n=7,738$ events) fIPSPs (reference) from the pre- and postseizure periods, shown as average traces on top (spontaneous, black; evoked, blue; scale bar, $100 \mu \mathrm{V}$ ) at the same timescale and aligned on peak.

(E) Peri-event time histogram (mean \pm SEM, time bin $1 \mathrm{~ms}$ ) between firing activity ( $\mathrm{n}=3$ responding putative pyramidal cells from 2 mice of 42 cells from

7 mice) and optogenetically evoked fIPSPs (reference) in the periods right after the seizures ( $n=18$ fIPSPs from 4 seizures with excited putative pyramidal cells, out of a total of 14 seizures), shown as average traces on top at the same timescale and aligned on peak (scale bar, $100 \mu \mathrm{V}$ ). Note the clear time-locked excitation of pyramidal cell firing and reversed polarity of the fIPSPs evoked by the optogenetic stimulation of PV interneurons in the period right after the seizure.

contralateral hemisphere. Electrophysiological recordings from the drug-free hippocampal hemisphere displayed both interictal activity and ictal seizures, recognized as complex events lasting $30-40 \mathrm{~s}(33.7 \pm 12.3 \mathrm{~s}, \mathrm{n}=14$ seizures from 7 mice), even though the animal did not display behavioral convulsions. Optogenetic stimulations (2 ms, $0.5 \mathrm{~Hz}$ ) were delivered without interruption throughout the recording session, even though we observed that spontaneous and evoked fIPSPs were transiently interrupted upon ictal seizure onset. While in comparison to baseline, the amplitude profiles of fIPSPs were not significantly affected between epileptic discharges, they transiently appeared with a reversed polarity after the termination of ictal seizures (cf. Figure 4C, latency to normal polarity, 219-550 s, $473.8 \pm$ 140.5 s, n = 7 mice totalizing 14 seizures; cf. Figure S3A for a representative example from a single animal and Figure S3B from a single seizure from another animal), suggesting transiently reversed polarity of GABAergic transmission after ictal seizures, but not after acute interictal spikes.

\section{Time-locked excitation of pyramidal cells}

Reversed fIPSP-associated perisomatic GABAergic transmission often ( $n=9$ over 14 seizures from 7 mice) could entrain the discharge of postsynaptic target neurons, as illustrated by the short-latency APs evoked after fIPSPs in the traces of Figure S2A and in the peri-event histogram between reversed fIPSPs and pyramidal cell firing activity in Figure 4E ( $n=3$ cells from a total of 42 putative pyramidal cells). The short latency (range 1-3 ms) between fIPSP onset and pyramidal spike firing is compatible with direct excitation but not with previously described rebound from inhibition (Cobb et al., 1995; Assaf and Schiller, 2016; Chang et al., 2018). No more fIPSP-related excitatory interactions were seen after the recovery of the polarity of fIPSPs. These results suggest that an ictal seizure can entrain transient depolarizing and excitatory actions of perisomatic GABAergic transmission in the CA3 circuit. Nevertheless, the expression of excitatory GABA, in terms of time-locked postsynaptic AP firing, was 
A

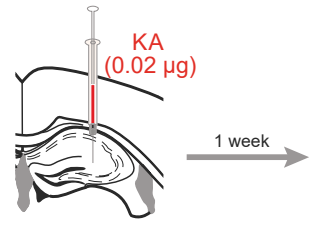

B

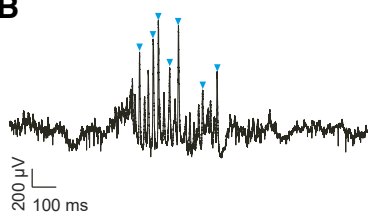

E
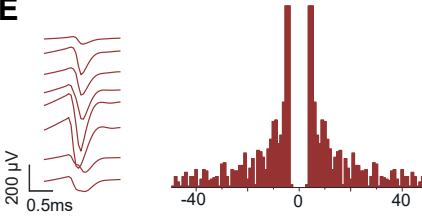

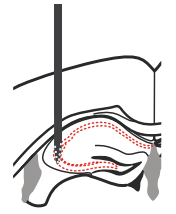

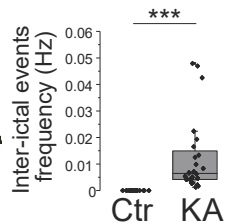

C

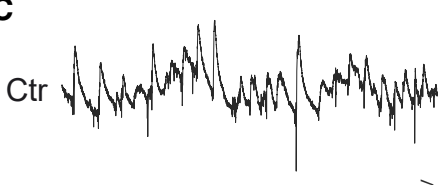

D
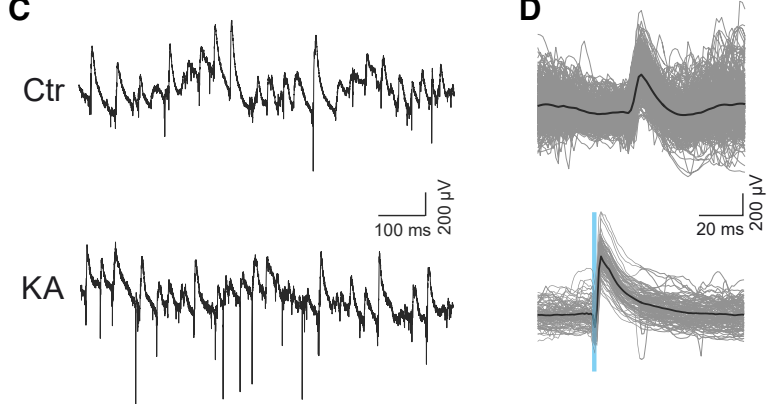

$\mathbf{F}$
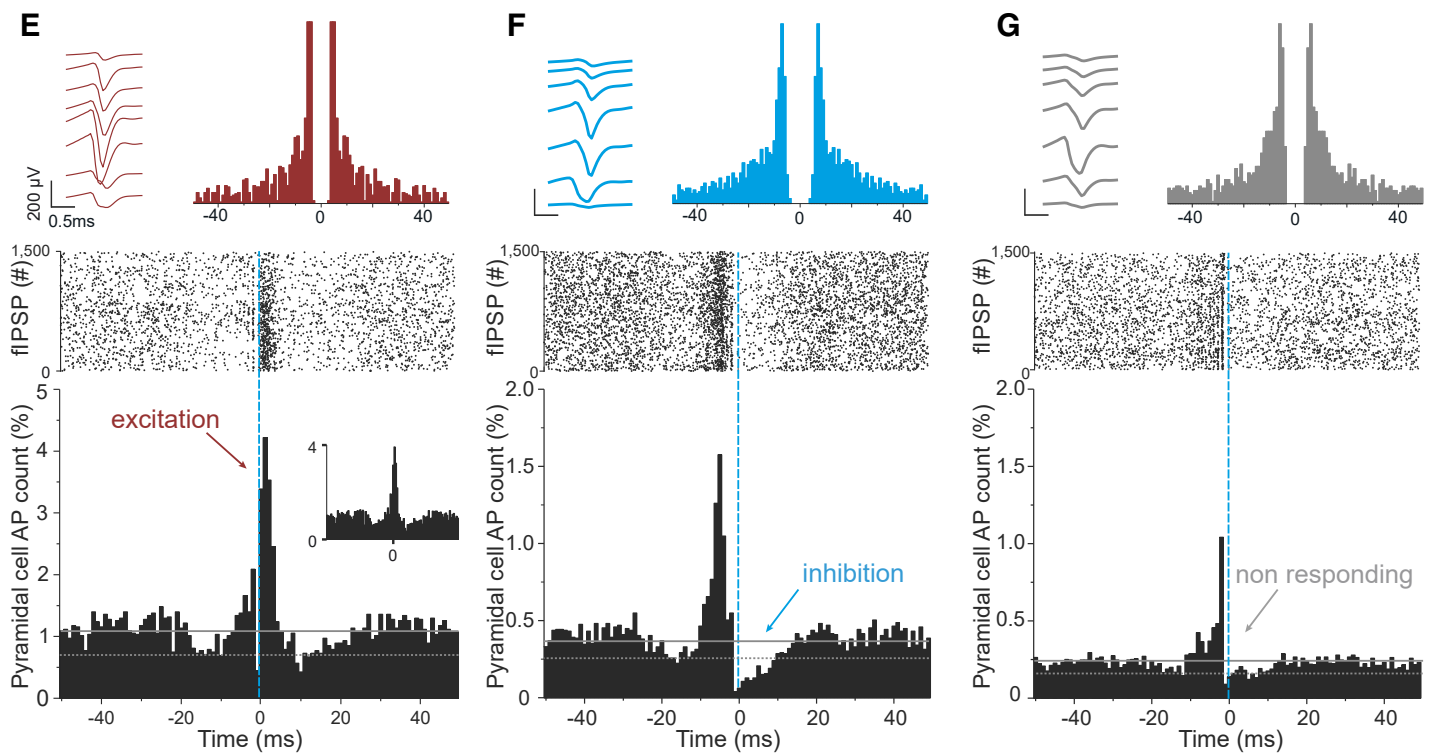

Figure 5. Normal fIPSP polarity but GABA-mediated time-locked excitation in head-fixed KA-treated mice

(A) CA3 neuronal activity was recorded from urethane-anesthetized WT mice 1 week after contralateral, intrahippocampal KA injection.

(B) Example trace (wide-band LFP) of interictal burst (interictal spikes, blue arrowheads; scale bars, $100 \mathrm{~ms}, 200 \mu \mathrm{V}$ ), and summary plot ( $\mathrm{n}=18 \mathrm{control}$ and $23 \mathrm{KA}$ treated mice) of interictal event frequency of occurrence $(\mathrm{Hz})$.

(C) Example traces of spontaneous CA3 pyramidal layer activity in control (top) and KA (bottom) conditions. Scale bars, $100 \mathrm{ms,} 200 \mu \mathrm{V}$.

(D) Superimposed (gray) and averaged (black) traces of spontaneous (top) or optogenetically evoked (bottom) flPSPs in KA-treated mice. Scale bars, 20 ms, $200 \mu \mathrm{V}$. Note the presence of normal polarity fIPSPs in both conditions.

(E-G) Individual examples of putative pyramidal cells displaying the 3 distinct types of observed responses to spontaneous fIPSP-associated events in KAtreated mice (time-locked excitation [E], time-locked inhibition [F], or no clear change in net firing rate [G, non-responding]). Upper left, average waveforms from the 8 channels of the recording electrode. Scale bars, $0.5 \mathrm{~ms}, 200 \mu \mathrm{V}$. Upper right, spike autocorrelogram. Center, raster display of spike firing aligned on flPSP occurrence (vertical blue line, fIPSP peak). Lower plot, normalized peri-event time histogram (time bin, $1 \mathrm{~ms}$ ) of the neuron discharge (AP count) relative to fIPSP peak (reference, vertical blue line). Inset of $(\mathrm{E})$, similar peri-event time histogram but ignoring AP bursts (i.e., all spikes with preceding interspike interval $<10$ ms omitted from the histogram).

restricted to $<10 \%$ of the putative pyramidal cells identified, and confined to the postictal period devoid of spontaneous neuronal activity.

\section{Discrete excitatory perisomatic GABAergic} transmission in a chronic model of epilepsy Acute ictal seizures, as induced experimentally by the injection of the convulsive agent kainic acid (KA), can turn into chronic epilepsy after a silent period of up to several weeks. Previous studies on various models of epilepsy have suggested that reversed (excitatory) GABAergic transmission may be involved in the transition between acute seizures and chronic epilepsy (Pathak et al.,
2007; Bragin et al., 2009; Barmashenko et al., 2011; Nardou et al., 2011; Töpfer et al., 2014; Kourdougli et al., 2017). This condition is of high clinical relevance because incident occurrence of isolated seizures in humans is known to be a main factor in the development of chronic epilepsy after a latent period that can last from months to several years (French et al., 1993). Identifying the cellular mechanisms responsible for this transition may offer opportunities for preventive treatment against epilepsy.

\section{Unchanged fIPSP polarity}

We have evaluated the dynamics of perisomatic inhibition in the CA3 hippocampal region of anesthetized KA-treated mice during the latent period, 1 week after KA injection in the contralateral 
hippocampus - therefore at a stage when the animals are not yet epileptic (Riban et al., 2002). All KA-treated mice experienced acute status epilepticus. One week later, as illustrated in Figure $5 \mathrm{~B}$, interictal discharges were present in all KA-treated mice (frequency of occurrence, $0.012 \pm 0.014 \mathrm{~Hz}, \mathrm{n}=23$ mice), but in none of the control animals ( $n=18$ mice). As illustrated in Figure 5C, among all identified fIPSPs, none appeared of reversed polarity, whether spontaneous or evoked by the optogenetic activation of PV interneurons, in control $(n=18$ WT and 5 PV-ChR2 mice injected with Cre-dependent ChR2) or in KAtreated mice ( $\mathrm{n}=8 \mathrm{WT}$ and $15 \mathrm{PV}-\mathrm{ChR} 2$ mice injected with Cre-dependent ChR2), suggesting that GABAergic transmission was globally hyperpolarizing at the network level. Nevertheless, because the polarity of fIPSPs represents the average response of all of the local pyramidal targets of the discharging presynaptic interneuron(s), the possibility remained that a subpopulation of pyramidal cells may be depolarized or even excited by GABAergic transmission in spite of a globally hyperpolarizing fIPSP-associated population response. We have therefore evaluated the responses of individual cells to spontaneous fIPSPassociated events, and identified some neurons that fired APs in response to GABAergic synaptic inputs.

\section{Altered perisomatic GABAergic transmission}

Individual examples of putative pyramidal cells displaying the three distinct types of observed responses to spontaneous fIPSP-associated events (time-locked excitation, time-locked inhibition, or no clear change in net firing rate) are illustrated in Figure 5 . None of the cells recorded in control animals showed GABAergic excitation ( $n=0$ of 389 putative pyramidal cells from 18 mice); excitatory GABAergic transmission expressed in KA-treated mice was the exception. It was observed only in a minority of animals ( $n=3$ of $23 \mathrm{KA}$-treated mice), and even in those animals, in a minority of neurons ( $n=4$ of 78 putative pyramidal cells from $3 \mathrm{KA}$-treated mice), for a global incidence of $0.6 \%$ of all putative pyramidal cells recorded from KA-treated mice ( $n=4$ of 707 putative pyramidal cells, recorded from 23 KA-treated mice). In fact, the most striking alteration of perisomatic inhibitory function in KA-treated mice was a loss of inhibitory control over most pyramidal neurons.

As illustrated in Figure 6, the frequency of occurrence of fIPSPs was not significantly different in control and KA-treated mice (control, $7.99 \pm 3.39 \mathrm{~Hz}, \mathrm{n}=18$ mice; KA-treated, $8.51 \pm$ $2.96 \mathrm{~Hz}, \mathrm{n}=23$ mice; $\mathrm{t}(39)=-0.52, \mathrm{p}=0.6)$, and neither was the distribution of spontaneous or evoked fIPSP amplitudes (2way ANOVA, $F(39)=0.54, p=0.98$ for spontaneous, $F(39)=$ $0.79, p=0.8$ for evoked). In both KA-treated and control mice, fIPSPs displayed some rhythmicity at gamma frequency, as indicated by the $25-\mathrm{ms}$ (i.e., $40 \mathrm{~Hz}$ ) peak in the distribution of interevent intervals displayed in Figures $6 \mathrm{C}$ and S5, and showed a similar preference for the downward phase of theta oscillations (cf. Figures 6B and S4), which is in line with the previously described theta phase locking of PV-basket cell activity (Klausberger and Somogyi, 2008). Significant theta phase locking of fIPSPs was found for both control and KA-treated mice (Rayleigh test, $p<0.001)$. The preferred phase $(\mu)$ was $1.15 \pm 0.11 \pi$ in control and $1.12 \pm 0.18 \pi$ in KA-treated mice $(t(14)=-0.39, N S)$. The modulation strength $(\kappa)$ was $0.57 \pm 0.22$ in control and $0.49 \pm$ 0.13 in KA-treated mice $(\mathrm{t}(14)=-0.86, \mathrm{NS})$. However, only
$45.1 \% \pm 30.6 \%$ of putative pyramidal cells were inhibited by spontaneous fIPSP-associated events in KA-treated mice (median $38.8 \%, n=17$ mice, for a total of 572 cells) versus $71.7 \%$ $\pm 12.9 \%$ in control animals (median $71.7 \%, n=18$ mice, for a total of 389 cells; Mann-Whitney test, $p<0.05$ ). Putative pyramidal cells from KA-treated mice that were inhibited by fIPSP-associated events presented the same strength and kinetics of inhibition as neurons from control mice (strength of inhibition: control, $90.6 \% \pm 1.9 \%, n=18$ mice, for a total of 280 inhibited pyramidal cells; KA-treated, $90.8 \% \pm 9.2 \%, n=23$ mice, for a total of 346 inhibited pyramidal cells, NS, Mann-Whitney test, $p=0.87$; time before recovery from inhibition: control, $7.92 \pm 1.85 \mathrm{~ms}$, $\mathrm{n}=18$ mice, for a total of 280 pyramidal cells; KA-treated, 8.22 $\pm 1.73 \mathrm{~ms}, \mathrm{n}=23$ mice, for a total of 346 pyramidal cells, NS, Mann-Whitney test, $p=0.2$ ), and the kinetics of fIPSPs were similar in control and KA-treated mice (rise time: $1.98 \pm$ $0.15 \mathrm{~ms}, \mathrm{n}=5$ control mice, $1.67 \pm 0.15 \mathrm{~ms}, \mathrm{n}=5 \mathrm{KA}$-treated mice, NS, 2-sample t test, $p=0.093$; decay time constant: $4.11 \pm 0.73 \mathrm{~ms}, \mathrm{n}=5$ control mice, $4.68 \pm 1.17 \mathrm{~ms}, \mathrm{n}=5 \mathrm{KA}-$ treated mice, NS, 2-sample t test, $p=0.39$ ). Overall, pyramidal population activity was nevertheless $\sim 50 \%$ lower in KA-treated mice than in controls (control, $0.81 \pm 0.32 \mathrm{~Hz}, \mathrm{n}=18$ mice, for a total of 389 pyramidal cells; KA-treated, $0.39 \pm 0.23 \mathrm{~Hz}, \mathrm{n}=$ 23 mice, for a total of 703 pyramidal cells; Mann-Whitney test, $\mathrm{p}<0.001$ ), in line with the hypothesis that perisomatic inhibitory function is not the main determinant of quantitative population activity in the CA3 hippocampal circuit. In future studies, it may be interesting to investigate at various delays after an acute seizure episode whether the observed interindividual heterogeneity in the fate of perisomatic inhibitory function across KAtreated mice is involved in the distinct phenotypic outcome of individual animals differentially affected by the initial insult.

\section{DISCUSSION}

\section{CA3 fIPSPs to reveal the spontaneous dynamics of} GABAergic transmission in vivo

The possibility that altered $\left[\mathrm{Cl}^{-}\right] \mathrm{i}$ regulation and functionally reversed GABAergic transmission (from inhibitory to excitatory) may be involved in major pathologies such as epilepsy, autism spectrum disorders, or schizophrenia has recently engendered considerable interest (Pathak et al., 2007; Kahle and Staley, 2008; Bragin et al., 2009; Barmashenko et al., 2011; Nardou et al., 2011; Löscher et al., 2013; Tyzio et al., 2014; Deidda et al., 2015; Marguet et al., 2015; Doyon et al., 2016; MacKenzie et al., 2016; Ben-Ari, 2017; Chen et al., 2017; Moore et al., 2017; Wang et al., 2017; Kharod et al., 2019). However, a direct assessment of this hypothesis has been hindered by the technical difficulty of probing endogenous GABAergic synaptic function in vivo because it implies minimized perturbation of cytoplasmic content, membrane potential, and natural synaptic GABAergic activity (Gulledge and Stuart, 2003; Tyzio et al., 2008; Magloire et al., 2019). The difficulties reside in both the recording methods and the activation of GABAergic transmission. Neuronal $\left[\mathrm{Cl}^{-}\right] \mathrm{i}$ is very labile and even intracellular recordings with sharp electrodes, which limit cytoplasmic washout, do not preserve membrane integrity, potentially altering resting potential and endogenous $\mathrm{Cl}^{-}$gradient. Patch clamp (cell- 
A

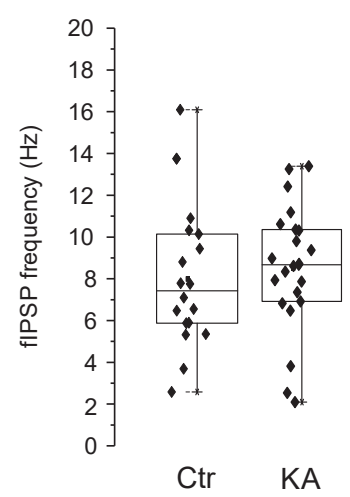

F

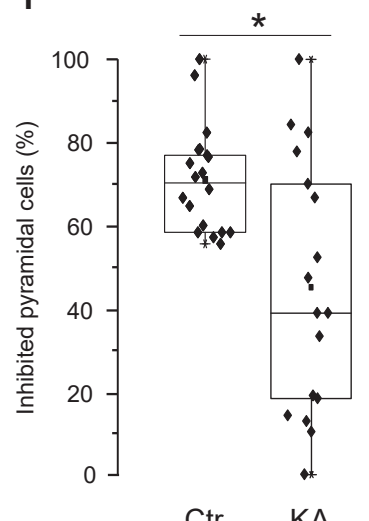

B

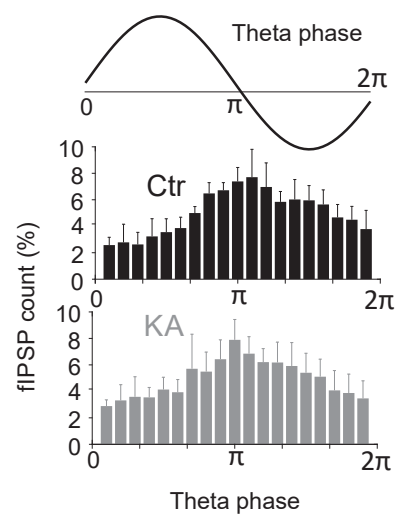

G

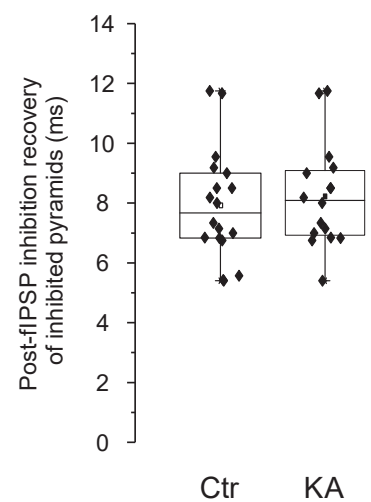

C

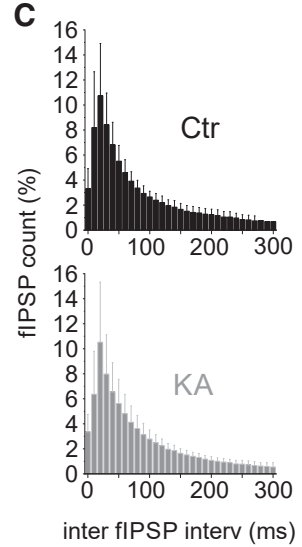

H

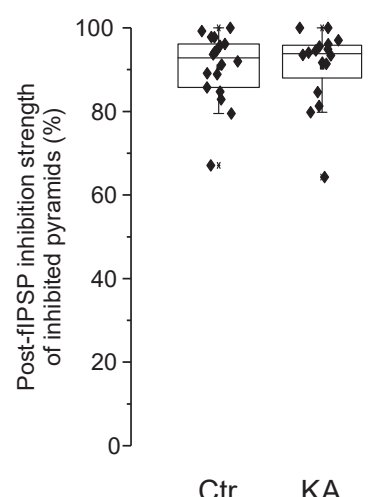

D

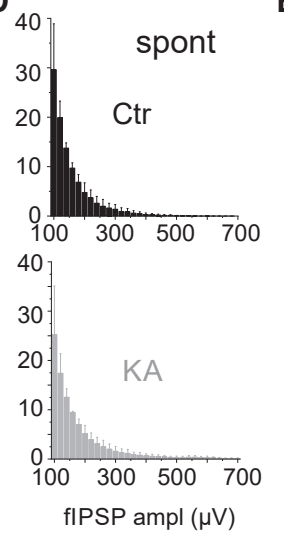

E

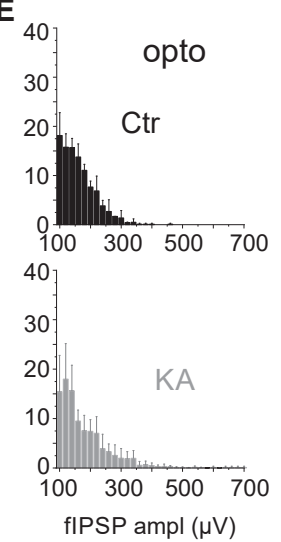

Figure 6. Loss of perisomatic inhibition in a majority of CA3 pyramidal cells during the latent, pre-epileptic period

Summary boxplots and histogram distributions of various parameters of neuronal activity and perisomatic inhibition in CA3 putative pyramidal cells in control (Ctr, $\mathrm{n}=18$ mice for a total of 389 cells for all of the plots, except in (B), in which only $n=9$ mice expressing reliable theta oscillations were included) and KA-treated mice ( 1 week post-KA injection, $n=23$ mice for a total of 703 cells for all of the plots, except in (B), in which only $n=8$ mice expressing reliable theta oscillations were included). ${ }^{*} p<0.05,{ }^{* \star *} p<0.001$.

(A) Frequency of fIPSPs occurrence (Hz).

(B) fIPSPs theta phase distribution (normalized fIPSP count, \%, mean \pm SD).

(C) Interevent (fIPSPs) time interval distribution (normalized fIPSP count, \%, mean \pm SD).

( $D$ and E) Amplitude distribution (normalized fIPSP count, mean \pm SD) of spontaneous (spont) and optogenetically evoked (opto) fIPSPs.

(F) Proportion of pyramidal cells inhibited by spontaneous fIPSP-associated events (\%).

(G) Latency to recovery (ms) from perisomatic inhibition for neurons that were actually inhibited by fIPSP-associated events (last of post-fIPSPs time bin with firing rate below baseline, $2 \mathrm{SD}$ ).

(H) Strength of perisomatic inhibition (percentage of firing inhibition in the bin of minimum firing in the 4-ms post-fIPSPs) for neurons that were actually inhibited by fIPSP-associated events.

(I) Average pyramidal firing rate ( $\mathrm{Hz})$. Note the loss of perisomatic inhibitory control (i.e., non-responding cells) in the majority of pyramidal cells in KA-treated mice but the normal inhibition in responding neurons (inhibited by fIPSP-associated events).

See also Figures S4 and S5.

attached) recordings are challenging in vivo, yield information about a single neuron at a time, and potentially affect neuronal resting potential (Chavas and Marty, 2003), a major parameter for the function of GABAergic transmission. Imaging techniques (e.g., of calcium or chloride) are advantageous in terms of spatial resolution, but they do not offer the time resolution of electrophysiological recordings and become invasive when applied to deep structures. Calcium imaging, in addition, does not detect depolarizations that do not reach the threshold of calcium channel activation, and hardly discriminates between depolarizing and excitatory effects that can both result in calcium increases, for example, during a shunting depolarization not associated with AP firing (Kirmse et al., 2015) or $\mathrm{GABA}_{\mathrm{A}}$-induced calcium increases not mediated by changes in membrane potential (Chavas et al., 2004). As for the activation of $G_{A B A}-R$, neither the exogenous applications of GABAergic agonists nor the electrical or optogenetic activation of GABAergic inputs used in previous studies (Krook-Magnuson et al., 2013; Minlebaev et al., 2013; Astorga et al., 2015; Kirmse et al., 2015; Assaf and Schiller, 2016; Valeeva et al., 2016; Magloire et al., 2019) respect the dynamics of spontaneous synaptic transmission. For example, boosting $\mathrm{Cl}^{-}$ 
extrusion through KCC2 was recently shown to prevent the prolongation of seizures induced by the optogenetic activation of PV interneurons, but had no effect on spontaneous, ongoing seizures (Magloire et al., 2019). Therefore, in spite of a reversed $\mathrm{Cl}^{-}$gradient and GABAergic polarity with important functional consequences if activated optogenetically, it remains unclear whether excitatory GABAergic transmission functionally participated in spontaneous ongoing seizure activity. Another caveat is that different types of interneurons interact with each other, such as the mutually inhibiting PV and somatostatin (SOM)-expressing interneurons (Lovett-Barron et al., 2012). Experimental manipulation of specific interneurons (e.g., PV) may therefore also influence seizure expression indirectly by the modulation of pyramidal cells' GABAergic inputs from other interneurons. This illustrates the potential confound of interpreting the effects of GABAergic activation at the network level rather than obtaining a direct readout of monosynaptic, spontaneous GABAergic transmission.

Previous work in vitro suggested that the direct postsynaptic response of hippocampal pyramidal cells to their spontaneously occurring perisomatic GABAergic inputs could be recorded extracellularly, as fIPSPs, and that the polarity of fIPSPs could be used as an index of the $\mathrm{Cl}^{-}$gradient and polarity of GABAergic transmission. Perisomatically projecting interneurons (basket and chandelier cells) have a densely arborized axon specifically confined to the pyramidal cell layer and contact a large proportion of pyramidal cells within a restricted projection area (Buhl et al., 1994; Sik et al., 1995). Therefore, each AP of the interneuron triggers the nearly synchronous release of GABA on hundreds of target pyramidal cells, which postsynaptic responses (IPSPs) sum up and can be readily identified from a local extracellular electrode (Glickfeld et al., 2009; Bazelot et al., 2010; Beyeler et al., 2013). In vitro investigations in controlled experimental conditions have moreover demonstrated that the polarity of fIPSPs reflected that of the $\mathrm{Cl}^{-}$gradient (Glickfeld et al., 2009; Bazelot et al., 2010). This approach is well suited to preserving endogenous $\left[\mathrm{Cl}^{-}\right] \mathrm{i}$, can be performed in vivo, and opens the possibility of resolving the dynamics of the $\mathrm{Cl}^{-}$gradient and polarity of GABAergic transmission over the course of ongoing synaptic activity. A strong limitation, however, is that fIPSPs are the average response of multiple pyramidal cells and therefore lack the resolution of individual cells, so that changes in GABAergic polarity can be detected if they affect the whole neuronal population, but may be missed if affecting only a subset of cells. Moreover, as mentioned before, GABAergic transmission involves both voltage and conductance changes, so that reversed $\mathrm{Cl}^{-}$gradient and depolarizing GABA carry a complex combination of excitatory (through depolarization) and inhibitory (through increased conductance) influences (Staley and Mody, 1992; Lu and Trussell, 2001; Gulledge and Stuart, 2003; Tyzio et al., 2008; Khalilov et al., 2015; Kirmse et al., 2015). As a consequence, determining the net postsynaptic effect of GABAergic transmission requires a direct readout of postsynaptic firing activity. For all of these reasons, we now propose that the method of choice to probe $\mathrm{Cl}^{-}$gradient and GABAergic synaptic function in vivo lies in combined multi-electrode recording and spikesorting methods. While fIPSPs provide the timing and global (average) polarity of spontaneous perisomatic GABAergic syn- aptic events, the distributions (peri-event time histograms) of the spikes of individually identified neurons provide the net functional effect of GABAergic transmission, with single-cell resolution.

Qualitative versus quantitative control of CA3 pyramidal cell activity by perisomatic inhibition from PV

interneurons

In line with previous in vitro evidence for the direct involvement of basket and chandelier cells in the generation of fIPSPs (Glickfeld et al., 2009; Bazelot et al., 2010; Beyeler et al., 2013), we provide direct evidence that in vivo fIPSPs originate mostly from PV interneurons, with little contribution from CCK basket cells, because they were elicited by the optogenetic activation of PV interneuronal firing and largely eliminated by the chemogenetic inhibition of PV interneuronal firing. Perisomatic inhibition is considered to be functionally optimal for the control of neuronal discharge, with synapses strategically located on the soma and close to the site of AP initiation (Miles et al., 1996; Somogyi and Klausberger, 2005). PV and CCK basket as well as chandelier cells are thus considered to play a major role in the control of pyramidal cells firing through time-locked inhibition, presumably preventing excessive firing within the hippocampal circuit. However, in spite of the critical importance of inhibitory control over the recurrent CA3 circuit, the literature is strikingly bereft of direct reports of the dynamics of excitatory-inhibitory interactions in CA3, presumably because of the technical difficulties of identifying perisomatic inhibitory events in vivo. Our experimental results confirm that perisomatic GABAergic transmission provides powerful time-locked inhibition of most CA3 pyramidal neurons. An interesting observation is that the blockade of PV interneuron firing was not accompanied by any major quantitative change of activity at the network level. This suggests that in the CA3 hippocampal region, perisomatic inhibition by PV basket cells may be involved in the control of the timing of pyramidal cell discharge rather than quantitative control of the network discharge. Previous reports are compatible with this hypothesis. In a previous study conducted in vitro (Beyeler et al., 2013), we reported that fIPSPs were rather poorly recruited by network activity, suggesting that perisomatic inhibition should be more efficient in shaping the timing of spike flow than in limiting excitatory runaway recruitment and preventing the generation of hypersynchronized discharges. Previous reports that transgenic mice with specifically disrupted glutamatergic inputs to $\mathrm{PV}^{+}$interneurons displayed hippocampo-dependent spatial memory impairment but no epileptic phenotype also support this interpretation (Fuchs et al., 2007; Rácz et al., 2009).

\section{Detection of alterations in GABAergic perisomatic} inhibition in epileptogenesis

One major advantage offered by the extracellular recording of fIPSPs is the possibility of evaluating the efficiency, and even the polarity, of perisomatic GABAergic transmission in a variety of conditions, including pathological conditions in which GABAergic transmission is suspected to be affected, or even reversed, due to altered neuronal $\mathrm{Cl}^{-}$homeostasis. The $\mathrm{Cl}^{-}$ gradient is dependent on a number of factors, including membrane potential, the distribution of intra- and extracellular 
impermeant anions, osmotic pressure, ionic content of the extracellular milieu (e.g., $\left[\mathrm{K}^{+}\right]$), recent neuronal activity involving $\mathrm{Cl}^{-}$ currents, and the dynamics of pumps and transporters involved in maintaining physiological $\mathrm{Cl}^{-}$gradient (Glykys et al., 2014; Goutierre et al., 2019). Our experiments have tested the possibility of detecting the short- and long-term consequences of acute seizures on $\mathrm{Cl}^{-}$regulation and GABAergic transmission, which is particularly important in understanding the mechanisms of epileptogenesis and identifying therapeutic actions against the development of epilepsy. We report that transient hypersynchronized discharges can induce a global reversal of neuronal $\mathrm{Cl}^{-}$gradient and polarity of GABAergic transmission, shifting from inhibitory to excitatory for a duration of several tens of seconds before returning to normal polarity and efficiency. The strongly depolarized membrane potential induced by ictal seizures (depolarizing block) is not in favor of a depolarizing $\mathrm{Cl}^{-}$gradient and excitatory GABAergic transmission. However, subsequent neuronal hyperpolarization is likely to occur due to the activation of $\mathrm{Ca}$-dependent potassium channels activated by the massive $\mathrm{Ca}$ increase that takes place in neurons during the postictal depolarizing block. We hypothesize that the fIPSPs of reversed polarity that were evoked after ictal seizures occurred during this period of strong neuronal hyperpolarization. Accordingly, we did not observe any fIPSPs immediately upon the termination of ictal seizures, and the transient reversal of $\mathrm{Cl}^{-}$electrochemical gradient and excitatory GABAergic transmission were confined to the period devoid of spontaneous neuronal firing. In line with recent work demonstrating the prolongation of seizures by reversed GABAergic transmission upon the optogenetic activation of PV interneurons but not during spontaneous activity (Magloire et al., 2019), our results highlight the importance of probing the polarity of spontaneous GABAergic synaptic transmission in addition to the responses evoked by artificial experimental stimulations.

While this reversal of GABAergic polarity in acute seizures is readily seen as a reversed polarity of fIPSPS, we also report a more subtle effect during the course of epileptogenesis in the $\mathrm{KA}$ model of chronic epilepsy. One week after KA injection, the majority of pyramidal cells had escaped inhibitory control by perisomatic GABAergic events. One possibility could be compromised synaptic transmission between PV interneurons and pyramidal cells, as reported earlier in the context of interictal activity (Karlócai et al., 2014). Our observation is, however, a statistical analysis, and we cannot exclude that the same neurons could be excited by some GABAergic events and inhibited by others (e.g., due to the fluctuations in time of the $\mathrm{Cl}^{-}$electrochemical gradient), resulting, on average, in the absence of a net effect of GABAergic transmission on postsynaptic AP firing. We observed that perisomatic GABAergic transmission provided time-locked excitation of pyramidal neurons in the hippocampus, but was restricted to a minor subset of neurons, and we did not observe a reversed polarity of fIPSPs. Therefore, subtle alterations in the regulation of $\mathrm{Cl}^{-}$homeostasis and GABAergic transmission already operated in the hippocampal circuit during the latent period that precedes the establishment of chronic epilepsy. Independent of seizure generation, deficient perisomatic inhibition may significantly affect neuronal processing and information coding. Moreover, even though our method specifically probes the functional transmission from perisomatically projecting $\mathrm{PV}$ interneurons, altered $\mathrm{Cl}^{-}$ gradient most likely affects GABAergic transmission from other types of interneurons as well. The functional consequences of defective GABAergic transmission, both in terms of coding and circuit dynamics, and in other periods, other models of epilepsy and other pathologies, remain to be investigated. From our recordings, we may hypothesize that excitatory GABAergic transmission may make a more limited contribution to CA3 hippocampal epileptogenesis than suspected from previous studies (Dzhala et al., 2005; Brandt et al., 2010; Barmashenko et al., 2011; Nardou et al., 2011; Ellender et al., 2014; Marguet et al., 2015; Chen et al., 2017; Kourdougli et al., 2017; Di Cristo et al., 2018), which was not based on direct in vivo evidence. However, we cannot exclude the decisive participation of excitatory GABA at different sites than where our recordings were performed. Previous work on human brain tissue resected from patients with epilepsy emphasized the potential involvement of excitatory GABA in the subiculum (Cohen et al., 2002; Huberfeld et al., 2007) or in the neocortex surrounding epileptogenic gliomas (Pallud et al., 2014). The exact contribution of excitatory GABA may depend on the exact brain area and identity of the affected neurons.

Finally, the extracellular detection of perisomatic IPSPs provides an invaluable tool to evaluate $\mathrm{Cl}^{-}$homeostasis and inhibitory function, in physiological conditions and in situations in which alteration or even reversal of GABAergic transmission is hypothesized to occur. This approach may open possibilities to evaluate the relevance of the excitatory GABA hypothesis in physiological development, autism spectrum disorders, schizophrenia, various forms of epilepsy, and the time course of epileptogenesis, as well as to evaluate the potential of pharmacological agents to interfere with neuronal $\mathrm{Cl}^{-}$gradient, as an effective therapeutic strategy against major brain diseases.

\section{Limitations of study}

Although our results support the primary involvement of perisomatically projecting interneurons (basket and axo-axonic) in the generation of fIPSPS, we cannot exclude the minor participation of other subtypes of interneurons projecting to the dendrites of pyramidal cells, such as bistratified or OLM cells. Regarding the significance of excitatory GABAergic transmission in epileptogenesis, excitatory GABA after acute seizures was confined to a period of neuronal silence and we did not observe a single neuron excited in the absence of laser stimulation ( $0 \%$ of cells were excited by spontaneously occurring fIPSPs). One week after KA-induced seizures (chronic model), we report that among 20 of $23 \mathrm{KA}$-treated mice ( $87 \%$ of animals), the incidence of excitatory GABA was 0 of 629 neurons $=0 \%$, and from the remaining 3 mice ( $13 \%$ of animals), it was 4 of 78 neurons = $5 \%-$ a global incidence of $0.6 \%$. These results do not support a significant role in epileptogenesis of excitatory GABA from CA3 perisomatically projecting PV interneurons, but they do not discard the possibility that GABA may exert excitatory actions at other synapses, between other neuronal types, in distinct areas than the precise locations of our recording electrodes (within or out of the recorded CA3 region), and in other models of epileptogenesis or other brain pathologies. 


\section{STAR $\star$ METHODS}

Detailed methods are provided in the online version of this paper and include the following:

- KEY RESOURCES TABLE

- RESOURCE AVAILABILITY

O Lead contact

O Materials availability

O Data and code availability

- EXPERIMENTAL MODEL AND SUBJECT DETAILS

- METHOD DETAILS

- Surgical procedures

- Genetic tools to manipulate PV interneurons

$O$ Head-restrained recordings

O Multi-site extracellular recording in vivo

$\bigcirc$ Histological processing

- QUANTIFICATION AND STATISTICAL ANALYSIS

O Spike sorting

O Event detection

O Reliability of fIPSP detection

Effects of perisomatic GABAergic events

Theta phase-locking

O Statistics

\section{SUPPLEMENTAL INFORMATION}

Supplemental information can be found online at https://doi.org/10.1016/j. celrep.2021.109381.

\section{ACKNOWLEDGMENTS}

We thank Roustem Khazipov, Rosa Cossart, Valérie Crepel, Tarek Deeb, and Isabel Del Pino for useful comments and discussions on a previous version of the manuscript; Delphine Gonzales, Nathalie Aubailly, and all of the personnel of the Animal Facility of the NeuroCentre Magendie for animal care; Katy Lecorf for help regarding virus preparation; the UMR5293 vector core facility for producing adeno-associated virus (AAV) vectors; and the laboratory of S.M. Sternson (Howard Hughes Medical Institute) for providing the chemical compound PSEM-89S. This work was performed thanks to the following funding sources: Inserm (X.L.), CNRS (X.L.), Région Nouvelle-Aquitaine (X.L.), the Japanese Society for the Promotion of Science (JSPS) (X.L. and H.H.), Agence Nationale de la Recherche (ANR) (X.L.), the Fondation Française pour la Recherche sur les Epilepsies (FFRE) (X.L.), and the French Ministry of Research and Education (O.D.). The funders had no role in study design, data collection and analysis, decision to publish, or preparation of the manuscript.

\section{AUTHOR CONTRIBUTIONS}

X.L. and H.H. performed the pilot experiments and initiated the study. X.L. conceived and designed the experiments. O.D. and X.L. planned the study. O.D., A.F.G.D.S., A.B., and X.L. performed the experiments. O.D. and X.L. analyzed the data. A.F. contributed lab and breeding space and a fraction of the operating expenses. O.D., A.B., and X.L. wrote the paper.

\section{DECLARATION OF INTERESTS}

The authors declare no competing interests.

Received: April 29, 2020

Revised: November 18, 2020

Accepted: June 18, 2021

Published: July 13, 2021

\section{REFERENCES}

Assaf, F., and Schiller, Y. (2016). The antiepileptic and ictogenic effects of optogenetic neurostimulation of PV-expressing interneurons. J. Neurophysiol. 116, 1694-1704.

Astorga, G., Bao, J., Marty, A., Augustine, G.J., Franconville, R., Jalil, A., Bradley, J., and Llano, I. (2015). An excitatory GABA loop operating in vivo. Front. Cell. Neurosci. 9, 275.

Barmashenko, G., Hefft, S., Aertsen, A., Kirschstein, T., and Köhling, R. (2011). Positive shifts of the GABAA receptor reversal potential due to altered chloride homeostasis is widespread after status epilepticus. Epilepsia 52, 1570-1578.

Bartho, P., Hirase, H., Monconduit, L., Zugaro, M., Harris, K.D., and Buzsaki, G. (2004). Characterization of neocortical principal cells and interneurons by network interactions and extracellular features. Journal of Neurophysiology 92, 600-608. https://doi.org/10.1152/jn.01170.2003.

Bazelot, M., Dinocourt, C., Cohen, I., and Miles, R. (2010). Unitary inhibitory field potentials in the CA3 region of rat hippocampus. J. Physiol. 588, $2077-$ 2090.

Ben-Ari, Y. (2017). NKCC1 Chloride Importer Antagonists Attenuate Many Neurological and Psychiatric Disorders. Trends Neurosci. 40, 536-554.

Berens, P. (2009). CircStat: A MATLAB Toolbox for Circular Statistics. J. Stat. Softw. 31. https://doi.org/10.18637/jss.v031.i10.

Beyeler, A., Retailleau, A., Molter, C., Mehidi, A., Szabadics, J., and Leinekugel, X. (2013). Recruitment of Perisomatic Inhibition during Spontaneous Hippocampal Activity In Vitro. PLoS ONE 8, e66509.

Blaesse, P., Airaksinen, M.S., Rivera, C., and Kaila, K. (2009). Cation-chloride cotransporters and neuronal function. Neuron 61, 820-838.

Bouilleret, V., Ridoux, V., Depaulis, A., Marescaux, C., Nehlig, A., and Le Gal La Salle, G. (1999). Recurrent seizures and hippocampal sclerosis following intrahippocampal kainate injection in adult mice: electroencephalography, histopathology and synaptic reorganization similar to mesial temporal lobe epilepsy. Neuroscience 89, 717-729.

Bragin, D.E., Sanderson, J.L., Peterson, S., Connor, J.A., and Müller, W.S. (2009). Development of epileptiform excitability in the deep entorhinal cortex after status epilepticus. Eur. J. Neurosci. 30, 611-624.

Brandt, C., Nozadze, M., Heuchert, N., Rattka, M., and Löscher, W. (2010). Disease-modifying effects of phenobarbital and the NKCC1 inhibitor bumetanide in the pilocarpine model of temporal lobe epilepsy. J. Neurosci. 30, 86028612.

Buhl, E.H., Han, Z.S., Lörinczi, Z., Stezhka, V.V., Karnup, S.V., and Somogyi, P. (1994). Physiological properties of anatomically identified axo-axonic cells in the rat hippocampus. J. Neurophysiol. 71, 1289-1307.

Cellot, G., and Cherubini, E. (2014). GABAergic signaling as therapeutic target for autism spectrum disorders. Front Pediatr. 2, 70.

Chang, M., Dian, J.A., Dufour, S., Wang, L., Moradi Chameh, H., Ramani, M., Zhang, L., Carlen, P.L., Womelsdorf, T., and Valiante, T.A. (2018). Brief activation of GABAergic interneurons initiates the transition to ictal events through post-inhibitory rebound excitation. Neurobiol. Dis. 109 (Pt A), 102-116.

Chavas, J., and Marty, A. (2003). Coexistence of excitatory and inhibitory GABA synapses in the cerebellar interneuron network. J. Neurosci. 23, 2019-2031.

Chavas, J., Forero, M.E., Collin, T., Llano, I., and Marty, A. (2004). Osmotic tension as a possible link between GABA(A) receptor activation and intracellular calcium elevation. Neuron 44, 701-713.

Chen, L., Wan, L., Wu, Z., Ren, W., Huang, Y., Qian, B., and Wang, Y. (2017). KCC2 downregulation facilitates epileptic seizures. Sci. Rep. 7, 156.

Cobb, S.R., Buhl, E.H., Halasy, K., Paulsen, O., and Somogyi, P. (1995). Synchronization of neuronal activity in hippocampus by individual GABAergic interneurons. Nature 378, 75-78.

Cohen, I., Navarro, V., Clemenceau, S., Baulac, M., and Miles, R. (2002). On the origin of interictal activity in human temporal lobe epilepsy in vitro. Science 298, 1418-1421. 
Csicsvari, J., Hirase, H., Czurko, A., and Buzsaki, G. (1998). Reliability and state dependence of pyramidal cell-interneuron synapses in the hippocampus: an ensemble approach in the behaving rat. Neuron 21, 179-189. https://doi.org/10.1016/s0896-6273(00)80525-5.

Deidda, G., Parrini, M., Naskar, S., Bozarth, I.F., Contestabile, A., and Cancedda, L. (2015). Reversing excitatory GABAAR signaling restores synaptic plasticity and memory in a mouse model of Down syndrome. Nat. Med. 21, 318-326.

Di Cristo, G., Awad, P.N., Hamidi, S., and Avoli, M. (2018). KCC2, epileptiform synchronization, and epileptic disorders. Prog. Neurobiol. 162, 1-16.

Donovan, M.D., Schellekens, H., Boylan, G.B., Cryan, J.F., and Griffin, B.T. (2016). In vitro bidirectional permeability studies identify pharmacokinetic limitations of NKCC1 inhibitor bumetanide. Eur. J. Pharmacol. 770, 117-125.

Doyon, N., Vinay, L., Prescott, S.A., and De Koninck, Y. (2016). Chloride Regulation: A Dynamic Equilibrium Crucial for Synaptic Inhibition. Neuron 89, 11571172.

Dzhala, V.I., Talos, D.M., Sdrulla, D.A., Brumback, A.C., Mathews, G.C., Benke, T.A., Delpire, E., Jensen, F.E., and Staley, K.J. (2005). NKCC1 transporter facilitates seizures in the developing brain. Nat. Med. 11, 1205-1213.

Dzhala, V., Valeeva, G., Glykys, J., Khazipov, R., and Staley, K. (2012). Traumatic alterations in GABA signaling disrupt hippocampal network activity in the developing brain. J. Neurosci. 32, 4017-4031.

Ellender, T.J., Raimondo, J.V., Irkle, A., Lamsa, K.P., and Akerman, C.J. (2014). Excitatory effects of parvalbumin-expressing interneurons maintain hippocampal epileptiform activity via synchronous afterdischarges. J. Neurosci. 34, 15208-15222.

French, J.A., Williamson, P.D., Thadani, V.M., Darcey, T.M., Mattson, R.H., Spencer, S.S., and Spencer, D.D. (1993). Characteristics of medial temporal lobe epilepsy: I. Results of history and physical examination. Ann. Neurol. 34, 774-780.

Fuchs, E.C., Zivkovic, A.R., Cunningham, M.O., Middleton, S., Lebeau, F.E., Bannerman, D.M., Rozov, A., Whittington, M.A., Traub, R.D., Rawlins, J.N., and Monyer, H. (2007). Recruitment of parvalbumin-positive interneurons determines hippocampal function and associated behavior. Neuron 53, 591-604.

Fujiwara-Tsukamoto, Y., Isomura, Y., Nambu, A., and Takada, M. (2003). Excitatory GABA input directly drives seizure-like rhythmic synchronization in mature hippocampal CA1 pyramidal cells. Neuroscience 119, 265-275.

Glickfeld, L.L., Roberts, J.D., Somogyi, P., and Scanziani, M. (2009). Interneurons hyperpolarize pyramidal cells along their entire somatodendritic axis. Nat. Neurosci. 12, 21-23.

Glykys, J., Dzhala, V., Egawa, K., Balena, T., Saponjian, Y., Kuchibhotla, K.V., Bacskai, B.J., Kahle, K.T., Zeuthen, T., and Staley, K.J. (2014). Local impermeant anions establish the neuronal chloride concentration. Science 343 , 670-675.

Goutierre, M., Al Awabdh, S., Donneger, F., François, E., Gomez-Dominguez, D., Irinopoulou, T., Menendez de la Prida, L., and Poncer, J.C. (2019). KCC2 Regulates Neuronal Excitability and Hippocampal Activity via Interaction with Task-3 Channels. Cell Rep. 28, 91-103.e7.

Gulledge, A.T., and Stuart, G.J. (2003). Excitatory actions of GABA in the cortex. Neuron 37, 299-309.

Hazan, L., Zugaro, M., and Buzsáki, G. (2006). Klusters, NeuroScope, NDManager: a free software suite for neurophysiological data processing and visualization. J. Neurosci. Methods 155, 207-216.

Hippenmeyer, S., Vrieseling, E., Sigrist, M., Portmann, T., Laengle, C., Ladle, D.R., and Arber, S. (2005). A developmental switch in the response of DRG neurons to ETS transcription factor signaling. PLoS Biol. 3, e159.

Huberfeld, G., Wittner, L., Clemenceau, S., Baulac, M., Kaila, K., Miles, R., and Rivera, C. (2007). Perturbed chloride homeostasis and GABAergic signaling in human temporal lobe epilepsy. J. Neurosci. 27, 9866-9873.

Kahle, K.T., and Staley, K.J. (2008). The bumetanide-sensitive Na-K-2Cl cotransporter NKCC1 as a potential target of a novel mechanism-based treatment strategy for neonatal seizures. Neurosurg. Focus 25, E22.
Karlócai, M.R., Kohus, Z., Káli, S., Ulbert, I., Szabó, G., Máté, Z., Freund, T.F., and Gulyás, A.I. (2014). Physiological sharp wave-ripples and interictal events in vitro: what's the difference? Brain 137, 463-485.

Khalilov, I., Holmes, G.L., and Ben-Ari, Y. (2003). In vitro formation of a secondary epileptogenic mirror focus by interhippocampal propagation of seizures. Nat. Neurosci. 6, 1079-1085.

Khalilov, I., Minlebaev, M., Mukhtarov, M., and Khazipov, R. (2015). Dynamic Changes from Depolarizing to Hyperpolarizing GABAergic Actions during Giant Depolarizing Potentials in the Neonatal Rat Hippocampus. J. Neurosci. $35,12635-12642$.

Kharod, S.C., Kang, S.K., and Kadam, S.D. (2019). Off-Label Use of Bumetanide for Brain Disorders: An Overview. Front. Neurosci. 13, 310.

Kirmse, K., Kummer, M., Kovalchuk, Y., Witte, O.W., Garaschuk, O., and Holthoff, K. (2015). GABA depolarizes immature neurons and inhibits network activity in the neonatal neocortex in vivo. Nat. Commun. 6, 7750 .

Klausberger, T., and Somogyi, P. (2008). Neuronal diversity and temporal dynamics: the unity of hippocampal circuit operations. Science 321, 53-57.

Kourdougli, N., Pellegrino, C., Renko, J.M., Khirug, S., Chazal, G., Kukko-Lukjanov, T.K., Lauri, S.E., Gaiarsa, J.L., Zhou, L., Peret, A., et al. (2017). Depolarizing $\gamma$-aminobutyric acid contributes to glutamatergic network rewiring in epilepsy. Ann. Neurol. 81, 251-265.

Krook-Magnuson, E., Armstrong, C., Oijala, M., and Soltesz, I. (2013). On-demand optogenetic control of spontaneous seizures in temporal lobe epilepsy. Nat. Commun. 4, 1376.

Lopez-Pigozzi, D., Laurent, F., Brotons-Mas, J.R., Valderrama, M., Valero, M., Fernandez-Lamo, I., Cid, E., Gomez-Dominguez, D., Gal, B., and Menendez de la Prida, L. (2016). Altered Oscillatory Dynamics of CA1 Parvalbumin Basket Cells during Theta-Gamma Rhythmopathies of Temporal Lobe Epilepsy. eNeuro 3, ENEURO.0284-0216.2016.

Löscher, W., Puskarjov, M., and Kaila, K. (2013). Cation-chloride cotransporters NKCC1 and KCC2 as potential targets for novel antiepileptic and antiepileptogenic treatments. Neuropharmacology 69, 62-74.

Lovett-Barron, M., Turi, G.F., Kaifosh, P., Lee, P.H., Bolze, F., Sun, X.H., Nicoud, J.F., Zemelman, B.V., Sternson, S.M., and Losonczy, A. (2012). Regulation of neuronal input transformations by tunable dendritic inhibition. Nat. Neurosci. 15, 423-430, S1-S3.

Lu, T., and Trussell, L.O. (2001). Mixed excitatory and inhibitory GABA-mediated transmission in chick cochlear nucleus. J. Physiol. 535, 125-131.

MacKenzie, G., O'Toole, K.K., Moss, S.J., and Maguire, J. (2016). Compromised GABAergic inhibition contributes to tumor-associated epilepsy. Epilepsy Res. 126, 185-196.

Magloire, V., Cornford, J., Lieb, A., Kullmann, D.M., and Pavlov, I. (2019). KCC2 overexpression prevents the paradoxical seizure-promoting action of somatic inhibition. Nat. Commun. 10, 1225.

Magnus, C.J., Lee, P.H., Atasoy, D., Su, H.H., Looger, L.L., and Sternson, S.M. (2011). Chemical and genetic engineering of selective ion channel-ligand interactions. Science 333, 1292-1296.

Marguet, S.L., Le-Schulte, V.T.Q., Merseburg, A., Neu, A., Eichler, R., Jakovcevski, I., Ivanov, A., Hanganu-Opatz, I.L., Bernard, C., Morellini, F., and Isbrandt, D. (2015). Treatment during a vulnerable developmental period rescues a genetic epilepsy. Nat. Med. 21, 1436-1444.

Mattis, J., Tye, K.M., Ferenczi, E.A., Ramakrishnan, C., O’Shea, D.J., Prakash, R., Gunaydin, L.A., Hyun, M., Fenno, L.E., Gradinaru, V., et al. (2011). Principles for applying optogenetic tools derived from direct comparative analysis of microbial opsins. Nat. Methods 9, 159-172.

Menendez de la Prida, L., and Trevelyan, A.J. (2011). Cellular mechanisms of high frequency oscillations in epilepsy: on the diverse sources of pathological activities. Epilepsy Res. 97, 308-317.

Miles, R., Tóth, K., Gulyás, A.I., Hájos, N., and Freund, T.F. (1996). Differences between somatic and dendritic inhibition in the hippocampus. Neuron 16, 815-823. 
Minlebaev, M., Valeeva, G., Tcheremiskine, V., Coustillier, G., and Khazipov, R. (2013). Cell-attached recordings of responses evoked by photorelease of GABA in the immature cortical neurons. Front. Cell. Neurosci. 7, 83.

Mitra, P.P., and Bokil, H. (2008). Observed Brain Dynamics (Oxford University Press).

Moore, Y.E., Kelley, M.R., Brandon, N.J., Deeb, T.Z., and Moss, S.J. (2017). Seizing Control of KCC2: A New Therapeutic Target for Epilepsy. Trends Neurosci. 40, 555-571.

Nardou, R., Yamamoto, S., Chazal, G., Bhar, A., Ferrand, N., Dulac, O., BenAri, Y., and Khalilov, I. (2011). Neuronal chloride accumulation and excitatory GABA underlie aggravation of neonatal epileptiform activities by phenobarbital. Brain 134, 987-1002.

Pallud, J., Le Van Quyen, M., Bielle, F., Pellegrino, C., Varlet, P., Labussiere, M., Cresto, N., Dieme, M.-J., Baulac, M., Duyckaerts, C., et al. (2014). Cortical GABAergic excitation contributes to epileptic activities around human glioma. Sci. Transl. Med. 6, 244 ra289.

Pathak, H.R., Weissinger, F., Terunuma, M., Carlson, G.C., Hsu, F.-C., Moss, S.J., and Coulter, D.A. (2007). Disrupted dentate granule cell chloride regulation enhances synaptic excitability during development of temporal lobe epilepsy. J. Neurosci. 27, 14012-14022.

Puskarjov, M., Kahle, K.T., Ruusuvuori, E., and Kaila, K. (2014). Pharmacotherapeutic targeting of cation-chloride cotransporters in neonatal seizures. Epilepsia 55, 806-818.

Rácz, A., Ponomarenko, A.A., Fuchs, E.C., and Monyer, H. (2009). Augmented hippocampal ripple oscillations in mice with reduced fast excitation onto parvalbumin-positive cells. J. Neurosci. 29, 2563-2568.

Riban, V., Bouilleret, V., Pham-Lê, B.T., Fritschy, J.M., Marescaux, C., and Depaulis, A. (2002). Evolution of hippocampal epileptic activity during the development of hippocampal sclerosis in a mouse model of temporal lobe epilepsy. Neuroscience 112, 101-111.

Riekki, R., Pavlov, I., Tornberg, J., Lauri, S.E., Airaksinen, M.S., and Taira, T. (2008). Altered synaptic dynamics and hippocampal excitability but normal long-term plasticity in mice lacking hyperpolarizing GABA A receptor-mediated inhibition in CA1 pyramidal neurons. J. Neurophysiol. 99, 3075-3089.

Römermann, K., Fedrowitz, M., Hampel, P., Kaczmarek, E., Töllner, K., Erker, T., Sweet, D.H., and Löscher, W. (2017). Multiple blood-brain barrier transport mechanisms limit bumetanide accumulation, and therapeutic potential, in the mammalian brain. Neuropharmacology 117, 182-194.

Rossant, C., Kadir, S.N., Goodman, D.F.M., Schulman, J., Hunter, M.L.D., Saleem, A.B., Grosmark, A., Belluscio, M., Denfield, G.H., Ecker, A.S., et al.
(2016). Spike sorting for large, dense electrode arrays. Nat. Neurosci. 19, 634-641.

Sik, A., Penttonen, M., Ylinen, A., and Buzsáki, G. (1995). Hippocampal CA1 interneurons: an in vivo intracellular labeling study. J. Neurosci. 15, 66516665.

Somogyi, P., and Klausberger, T. (2005). Defined types of cortical interneurone structure space and spike timing in the hippocampus. J. Physiol. 562, 9-26.

Staley, K.J., and Mody, I. (1992). Shunting of excitatory input to dentate gyrus granule cells by a depolarizing GABAA receptor-mediated postsynaptic conductance. J. Neurophysiol. 68, 197-212.

Sternson, S.M., and Roth, B.L. (2014). Chemogenetic tools to interrogate brain functions. Annu. Rev. Neurosci. 37, 387-407.

Töpfer, M., Töllner, K., Brandt, C., Twele, F., Bröer, S., and Löscher, W. (2014). Consequences of inhibition of bumetanide metabolism in rodents on brain penetration and effects of bumetanide in chronic models of epilepsy. Eur. J. Neurosci. 39, 673-687.

Tyzio, R., Minlebaev, M., Rheims, S., Ivanov, A., Jorquera, I., Holmes, G.L., Zilberter, Y., Ben-Ari, Y., and Khazipov, R. (2008). Postnatal changes in somatic gamma-aminobutyric acid signalling in the rat hippocampus. Eur. J. Neurosci. 27, 2515-2528.

Tyzio, R., Nardou, R., Ferrari, D.C., Tsintsadze, T., Shahrokhi, A., Eftekhari, S., Khalilov, I., Tsintsadze, V., Brouchoud, C., Chazal, G., et al. (2014). Oxytocinmediated GABA inhibition during delivery attenuates autism pathogenesis in rodent offspring. Science 343, 675-679.

Valeeva, G., Tressard, T., Mukhtarov, M., Baude, A., and Khazipov, R. (2016). An Optogenetic Approach for Investigation of Excitatory and Inhibitory Network GABA Actions in Mice Expressing Channelrhodopsin-2 in GABAergic Neurons. J. Neurosci. 36, 5961-5973.

Valero, M., Averkin, R.G., Fernandez-Lamo, I., Aguilar, J., Lopez-Pigozzi, D., Brotons-Mas, J.R., Cid, E., Tamas, G., and Menendez de la Prida, L. (2017). Mechanisms for Selective Single-Cell Reactivation during Offline SharpWave Ripples and Their Distortion by Fast Ripples. Neuron 94, 1234-1247.e7.

van den Pol, A.N., Obrietan, K., and Chen, G. (1996). Excitatory actions of GABA after neuronal trauma. J. Neurosci. 16, 4283-4292.

Wang, Y., Xu, C., Xu, Z., Ji, C., Liang, J., Wang, Y., Chen, B., Wu, X., Gao, F., Wang, S., et al. (2017). Depolarized GABAergic Signaling in Subicular Microcircuits Mediates Generalized Seizure in Temporal Lobe Epilepsy. Neuron 95, 92-105.e5. 


\section{STAR $\star M E T H O D S$}

\section{KEY RESOURCES TABLE}

\begin{tabular}{|c|c|c|}
\hline REAGENT or RESOURCE & SOURCE & IDENTIFIER \\
\hline \multicolumn{3}{|l|}{ Antibodies } \\
\hline $\begin{array}{l}\text { Mouse Monoclonal Anti-Parvalbumin } \\
\text { antibody }\end{array}$ & Sigma-Aldrich & Cat\# P3088; RRID:AB_477329 \\
\hline $\begin{array}{l}\text { Rabbit GFP Polyclonal Antibody, Alexa } \\
\text { Fluor } 488\end{array}$ & Thermo Fisher & Cat\# A-21311; RRID:AB_221477 \\
\hline Goat anti-Mouse IgG, Alexa Fluor 647 & Thermo Fisher & Cat\# A-21235; RRID:AB_2535804 \\
\hline \multicolumn{3}{|l|}{ Bacterial and virus strains } \\
\hline $\begin{array}{l}\text { AAV9-Ef1a-DIO hChR2(E123T/T159C)- } \\
\text { EYFP }\end{array}$ & Mattis et al., 2011 & Addgene Catalog \# 35509-AAV9 \\
\hline $\begin{array}{l}\text { rAAV-syn::FLEX-rev::PSAML141F:GlyR- } \\
\text { IRES-GFP }\end{array}$ & Magnus et al., 2011 & Addgene Catalog \# 32479 \\
\hline \multicolumn{3}{|c|}{ Chemicals, peptides, and recombinant proteins } \\
\hline PSEM-89S & $\begin{array}{l}\text { Scott Sternson, Janelia Farm } \\
\text { Research Campus, VA, USA }\end{array}$ & $\mathrm{N} / \mathrm{A}$ \\
\hline Bicuculline & Sigma Aldrich & Catalog \#14340 \\
\hline $\begin{array}{l}\text { Dil Stain (1,1'-Dioctadecyl-3,3,3', } \\
\text { 3'-Tetramethylindocarbocyanine } \\
\text { Perchlorate ('Dil'; DilC18(3))) }\end{array}$ & Thermofisher & Catalog number: D282 \\
\hline Urethane & Sigma Aldrich & Catalog \# U2500 \\
\hline ketamine (Imalgene 1000) & Merial & $\mathrm{N} / \mathrm{A}$ \\
\hline xylazine (Rompun 2\%) & Bayer & $\mathrm{N} / \mathrm{A}$ \\
\hline DAPI & Sigma Aldrich & Catalog \# D9542 \\
\hline \multicolumn{3}{|l|}{ Experimental models: organisms/strains } \\
\hline Mouse: B6;129P2-Pvalbtm1(cre)Arbr/J & Hippenmeyer et al., 2005 & JAX stock \#008069 \\
\hline Mouse: B6129SF2/J & $\mathrm{N} / \mathrm{A}$ & JAX stock \#101045 \\
\hline \multicolumn{3}{|l|}{ Software and algorithms } \\
\hline ImageJ & & https://imagej.net \\
\hline Imaris & Oxford Intruments & https://imaris.oxinst.com \\
\hline Neuroscope ndmanager & Hazan et al., 2006 & http://neurosuite.sourceforge.net \\
\hline KlustaSuite & Rossant et al., 2016 & https://www.ucl.ac.uk/cortexlab/ \\
\hline MiniAnalysis software & Synaptosoft Inc. & www.synaptosoft.com/MiniAnalysis \\
\hline Origin & OriginLab, Northampton, MA & https://www.originlab.com \\
\hline MATLAB & MathWorks & https://www.mathworks.com \\
\hline
\end{tabular}

\section{RESOURCE AVAILABILITY}

\section{Lead contact}

Further information and requests for resources and reagents should be directed to and will be fulfilled by the Lead Contact Xavier Leinekugel (xavier@arcadi.eu).

Materials availability

This study did not generate new unique reagents.

Data and code availability

The data shown in the paper and custom code for analysis supporting the current study will be made available from the corresponding author upon request. 


\section{EXPERIMENTAL MODEL AND SUBJECT DETAILS}

A total of 58 male adult mice (age 5-10 weeks, body weight 30-40 g) were used in this study. Animals were kept on a 12h:12h light (7am-7pm) / dark (7pm-7am) cycle and provided with ad libitum access to food and water. Among 32 transgenic mice expressing the Cre-recombinase under the control of the Parvalbumin promoter (PV-Cre, Hippenmeyer et al., 2005), Jackson Laboratory, B6;129P2Pvalbtm1(cre)Arbr/J), 27 were injected with Cre-dependent Channelrhodopsin2 (ChR2) for optogenetic activation of PV interneurons with light pulses delivered from a laser source through an optical fiber, among which 15 received an intrahippocampal injection of the convulsive agent kaïnic acid (Sigma-Aldrich Co., St Luis, MO), and 5 with the Cre-dependent Pharmacologically Selective Actuator Module fused to the glycine receptor (PSAM-GlyR) for chemogenetic silencing of PV-interneurons with the exogenous specific ligand PSEM-89S (Magnus et al., 2011; Sternson and Roth, 2014). Among 26 wild-type mice (B6129SF2), 8 received an intra-hippocampal injection of kainic acid, and the other 18 served as controls. All experimental procedures were performed in accordance with the EU directives regarding the protection of animals used for experimental and scientific purposes (86/609/EEC and 2010/63/EU), with the French law, and approved by the Ethical committee CEEA50 (saisines \#10894, 10896 and 19354).

\section{METHOD DETAILS}

\section{Surgical procedures}

The mice were anesthetized with isoflurane (1.5 - 5\%), placed in a stereotaxic frame (David Kopf Instruments) and kept on a thermal blanket (Physitemp) to maintain their body temperature at $37.5^{\circ} \mathrm{C}$. The eyes were covered with a protective liquid gel (Ocrygel). The scalp and periosteum over the dorsal surface of the skull were removed. For virus injection (optogenetic and chemogenetic constructions), a small craniotomy was executed at the coordinates of the left dorsal hippocampus (AP-1.6mm and L2.5mm relative to Bregma), and the injections (500nl measured using a Hamilton syringe, $2 \mathrm{~mm}$ deep from the brain surface) performed ( $\mathrm{n}=32 \mathrm{PV}-\mathrm{Cre}$ mice) using a thin glass capillary $(40-80 \mu \mathrm{m}$ at the tip). After injection, the capillary was maintained in situ for about $10 \mathrm{~min}$ before being slowly removed. The scalp was then sutured and the animal housed individually for 3-6 weeks before electrophysiological recording. For head-restrained experiments ( $n=7$ PV-Cre mice), reference and ground wires were implanted in the cerebellum and attached to a 2-pin connector, maintained together with a small custom-made horizontal stainless-steel bar anchored to the skull above the cerebellum with dental acrylic. A thin anchoring layer of dental acrylic (Super-Bond, Frapident) was applied on the exposed skull, except at specific locations in which a thin layer of bone was kept intact to allow for dorsal CA3 targeting with the recording silicon probe (left hemisphere, AP-1.6, L2.5, vertical insertion) and optical fiber (AP-1.6, L 3.2, insertion with an angle of $15^{\circ}$ from vertical) as well as contralateral (right hemisphere) dorsal hippocampus targeting of the capillary for bicuculline injection (AP-1.6 L1.5, insertion $20^{\circ}$ from vertical). For the study of chronic epileptogenesis ( $n=8$ WT mice and 15 PV-Cre mice injected with Cre-dependent ChR2), a craniotomy was performed above the dorsal hippocampus (right hemisphere, AP-1.6, L1.5) for vertical insertion of a capillary and injection of kainic acid $(0,2 \mu \mathrm{g}$ dissolved in saline, $500 \mathrm{nl}$ measured using a Hamilton syringe) at $1.8 \mathrm{~mm}$ from the brain surface. After injection, the capillary was maintained in situ for an additional $5 \mathrm{~min}$ before being slowly removed. The scalp was then sutured and the animal housed individually for 1 week before electrophysiological recording. As described in previous work (Bouilleret et al., 1999; Riban et al., 2002), 90\% of the mice injected with KA experience an initial status epilepticus followed by a latent period (i.e. without seizures) of about 2 weeks before expressing chronic epilepsy. We can therefore consider that most of the animals we recorded ( $n=23$ mice) were in a pre-epileptic state. Bicuculline, diazepam and kaïnic acid were purchased from Sigma-Aldrich Co., St Luis, MO.

Genetic tools to manipulate PV interneurons

For optogenetic excitation of PV interneurons, PV-Cre mice were injected with an adeno-associated virus (AAV) bearing ChR-2 with a YFP reporter (Mattis et al., 2011), pAAV-Ef1a-DIO hChR2 (E123T/T159C)-EYFP (gift from Karl Deisseroth, packaged into AAV serotype 9 from Addgene, plasmid \# 35509, initial viral titer $\geq 1 \times 10^{\star} 13 \mathrm{gcp} / \mathrm{ml}$, diluted four times in HBSS). Optogenetic activation (light wavelength $473 \mathrm{~nm}$, power max $10-14 \mathrm{~mW}, 2 \mathrm{~ms}$ pulses, $0.5 \mathrm{~Hz}$, driven by a train generator and current stimulator from Digitimer Ltd) was delivered through an optical fiber (diameter $200 \mu \mathrm{m}$ ) connected to a diode-pumped solid-state (DPSS) laser (Shangai instrument, $100 \mathrm{~mW}$ or IKECOOL Corporation). For chemogenetic inhibition of PV interneurons, we used an AAV bearing PSAM-GlyR with a GFP reporter, -rAAV-syn::FLEX-rev::PSAML141F,Y115F:GlyR-IRES-GFP (Addgene, gift from Scott Sternson, plasmid \# 32481, packaged into AAV serotype 9, initial viral titer $\geq 10^{*} 13 \mathrm{gcp} / \mathrm{ml}$, diluted four times in HBSS). PSAM-GlyR activation was performed by the injection of the specific ligand PSEM-89S (150-200nl, 15 $\mu \mathrm{M}$ in saline, obtained from Scott Sternson, Janelia Farm Research Campus, VA, USA), pressure-ejected into the left hippocampus from a glass capillary $(40-80 \mu \mathrm{m}$ at the tip).

\section{Head-restrained recordings}

The mice ( $n=7$ PV-Cre), previously implanted with head-posts, were maintained in the stereotaxic apparatus from their implanted fixation bars. Their body was inserted into a plastic tube (diameter approximately $5 \mathrm{~cm}$ ) to provide a reassuring confined environment and prevent excessive body movement. The animals readily habituated to head-fixed conditions. After initial training periods of a few minutes, restraint duration was gradually increased each day until the mouse would sit calmly for a period of roughly $1 \mathrm{~h}$. Electrophysiological recordings were performed after several days (at least five) of habituation. The dominant behavioral state in the 
head-restrained condition was awake immobility. On the day of recording, under brief isoflurane anesthesia (and body temperature control with a heating pad, $37.5^{\circ} \mathrm{C}$ ), the craniotomies were completed and the silicon probe, optical fiber and injection-capillary inserted. After $1 \mathrm{~h}$ recovery from anesthesia, and baseline recording, bicuculline was injected (100-200nl, $100 \mu \mathrm{M}$ in saline) into the right dorsal hippocampus to induce acute hippocampal seizures. At the end of the recording session, the animals were sacrificed and their brains removed for histological verification of electrode and optical fiber positions. The seizures induced in the head-restrained awake condition are most often not convulsive. In case of convulsion, the animal was immediately anesthetized with isoflurane and the experiment interrupted. This experimental aspect has been specifically submitted and approved by the local ethics committee $\left(E_{50}\right)$ and the final protocol validated by the French Government (saisine \#19355).

\section{Multi-site extracellular recording in vivo}

Extracellular recordings of spontaneous multi-unit activity and local field potentials were performed on mice either drug free in the head-restrained configuration ( $\mathrm{n}=7 \mathrm{PV}$-Cre mice) or anesthetized ( $\mathrm{n}=25 \mathrm{PV}$-Cre mice and $26 \mathrm{WT}$ mice) with urethane $(1.7 \mathrm{~g} / \mathrm{kg}$, $\mathrm{IP}$ ) and a complement of ketamine/xylazine (respectively 6.6 and $0.66 \mathrm{mg} / \mathrm{kg}$, IM, repeated whenever necessary, usually every 30 to $60 \mathrm{~min}$ ) and kept on a thermal blanket (Physitemp) to maintain their body temperature at $37.5^{\circ} \mathrm{C}$. Animals were fixed in the stereotaxic apparatus (David Kopf instrument), the craniotomy was performed, the dura was gently removed, and a multi-site silicon probe (Neuronexus Technologies, either A1x32-Poly3-5mm-25 s-177, 32 channels arranged on a single shank as 3 rows of vertically arranged staggered recording sites, vertical separation $25 \mu \mathrm{m}$, or Buzsaki16, 2 shanks separated by $200 \mu \mathrm{m}, 8$ recording sites each separated by $10-20 \mu \mathrm{m}$ ), covered with Dil (Molecular Probes) for post hoc verification of electrode position, was inserted vertically through the neocortex until the pyramidal layer of the CA3a hippocampal region. The stratum pyramidale was recognized by the presence of multiple firing cells and fIPSPs, and confirmed with the post hoc identification of Dil labeling. Recordings were performed using either Lynx-8 amplifiers (Neuralynx, gain x1000, bandpass filter $0.1 \mathrm{~Hz}$ to $9 \mathrm{KHz}$ ) and a digitizer (United Electronics, 14bits, A/D Gain $x 2$, sampling rate $20 \mathrm{KHz}$ ) controlled by a custom-made LabView (v7.1, National Instruments) program, or an integrated DigitalLynx SX system (Neuralynx, Cheetah v5.0 software, 24bits, sampling rate $32 \mathrm{KHz}$, bandpass $0.1 \mathrm{~Hz}$ to $9 \mathrm{KHz}$ and range $\pm 5 \mathrm{mV}$ for LFP analysis, as well as bandpass $1 \mathrm{~Hz}$ to $9 \mathrm{KHz}$ and range $\pm 1 \mathrm{mV}$ for spike sorting), and stored on a PC for offline analysis. The pyramidal layer was recognized electrophysiologically by the typical presence of fIPSPs and multi-unit firing. The recording started approximately 30 minutes after the insertion of the probe. Urethane was purchased from Sigma-Aldrich, ketamine (Imalgene 1000) from Merial and xylazine (Rompun 2\%) from Bayer.

\section{Histological processing}

At the end of the recording session, the animal was transcardially perfused with $4 \%$ paraformaldehyde. Coronal sections $(60 \mu \mathrm{m}-$ thick, cut using a VT1000S Leica vibratome) were blocked in 5\% Bovine Serum Albumin (BSA) and 0,25\% Triton X-100. After Tris-buffered saline washes, sections were incubated overnight at $4^{\circ} \mathrm{C}$ in $1 \% \mathrm{BSA}, 0,25 \%$ Triton $\mathrm{X}-100$ with mouse primary antibody against parvalbumin (1:200, Sigma-Aldrich Co., St Luis, MO) and rabbit antibody against GFP conjugated to Alexa Fluor 488 (1:2000, Thermo Fisher). After Tris-buffered saline washes, sections were then incubated with 1\% BSA, 0,25\% Triton X-100 and Alexa Fluor 647 conjugated goat antibody to mouse (1:500, Thermo-Fisher) $4 \mathrm{~h}$ at room temperature. After Tris-buffered saline washes, sections incubated 10 minutes with DAPI (1:1000 Sigma-Aldrich Co., St Luis, and MO) at room temperature. After washing, sections were mounted and coverslipped on slides. Confocal stack images from the CA3a hippocampal region were acquired and visualized with the ImageJ software. The number of GFP and PV-immunopositive cell bodies was counted on the stacks with the IMARIS software (Oxford instruments). To quantify co-localization, individual GFP labeled interneurons were identified and subsequently scored for PV immunoreactivity. Scans from each sample were collected in 3 slices per animal $(n=3$ ChR2 injected and 3 PSAM-GlyR injected PV-Cre mice).

\section{QUANTIFICATION AND STATISTICAL ANALYSIS}

Data were visualized and processed using NeuroScope and NDManager from the Neurosuite software (Hazan et al., 2006) (http:// neurosuite.sourceforge.net), and analyzed using Excel (Microsoft Office 2013), Origin (OriginLab, Northampton, MA) and MATLAB (MathWorks) built-in or custom-built procedures.

\section{Spike sorting}

The spikes were detected and extracted (SpikeDetekt), automatically clustered (KlustaKwik), and the resulting clusters manually verified and refined (KlustaViewa) using the KlustaSuite software (Rossant et al., 2016) (https://www.ucl.ac.uk/cortexlab/). Beside multiunit activity (MUA), only the clusters with a clear refractory period and typical bursting pattern of putative pyramidal cells were included in the analysis of neuronal firing (and referred to as pyramidal cells).

\section{Event detection}

The fIPSPs were detected with the MiniAnalysis software (6.0.3 Synaptosoft Inc.) from the raw signal using the following parameters (manually adjusted within the indicated ranges []): amplitude $(\mu \mathrm{V}), \min =100$, rise time $(\mathrm{ms}), \min =1, \max =[410]$, decay $(\mathrm{ms})$, $\min =[1$ 2], $\max =\left[\begin{array}{ll}6 & 10\end{array}\right]$, halfwidth $(\mathrm{ms}) \min =[12], \max =\left[\begin{array}{ll}6 & 10\end{array}\right.$, and decay10-90-slope $(\mu \mathrm{V} / \mathrm{ms}), \min =25, \max =[5001500]$. In results, the 
value taken for rise time is the time to peak (latency from onset to peak) while the decay time constant is the constant value of the exponential curve best fitting the decay of the event. Epileptiform events (inter-ictal spikes) were identified with MiniAnalysis as events of positive polarity and larger than 5 times the average amplitude of the detected fIPSPs. All detected events were verified by visual inspection.

\section{Reliability of fIPSP detection}

To evaluate the reliability of fIPSP detection in the context of in vivo neuronal dynamics requires ground truth information about the actual occurrence of perisomatic GABAergic events. From the postsynaptic responses (unitary field-potentials) to the optogenetic stimulation of PV interneurons (in which the ground truth is that of laser activation, $n=100$ events from each animal), we could estimate the proportions of evoked fIPSPs that have been successfully detected (true positives) versus those that have failed to be detected (false negatives). Beside a shift in the distribution of fIPSP amplitudes, a drop in the apparent success rate of evoked fIPSPs may also reveal the potential expression of "invisible" or undetectable fIPSPs due to reversed $\mathrm{Cl}^{-}$gradient in a subset of cells canceling the field response of other cells. The success rate of fIPSP detection in response to the optogenetic activation of PV interneurons (i.e. the proportion of optogenetic stimulations resulting in a detected fIPSP) in head-fixed mice was $76.7 \pm 10.4 \%$ in control ( $n=3$ mice) and $91 \pm 1.7 \%$ in the presence of the glutamatergic blockers APV and DNQX ( $n=3$ mice), and did not differ between control and KA-treated mice (respectively $74 \pm 9.6 \%, n=5$ mice, and $76 \pm 12.5 \%, n=9$ mice, $t(12)=-0.26, p=0.79$ ). Manual examination of the optogenetic stimulations which produced an undetected fIPSP (i.e. evoked fIPSPs missed by the detection algorithm, for example due to subthreshold amplitude) indicate that the proportion of false negatives in head fixed mice was $5 \pm 2 \%$ in control ( $n=3$ mice) and $2.3 \pm 0.6 \%$ in APV +NBQX ( $n=3$ mice), and did not differ between control and KA-treated mice (respectively $2.8 \pm 0.8 \%, n=5$ mice and $3.6 \pm 1.3 \%, n=9$ mice). The amplitude threshold for detection was set as to prevent artifactual detections (i.e. detected events that are not actual fIPSPs). Accordingly, there were no false positives (i.e. fIPSP detection in absence of an actual fIPSP) among optogenetically evoked fIPSPs in any of the conditions. From these results, we can estimate that the reliability of our detection algorithm is between 95 and $98 \%$ (i.e. 95 to $98 \%$ of emitted fIPSPs are properly captured with our detection parameters), and that the reliability of the fIPSP approach (i.e. the emission of a fIPSP in response to the stimulation of PV interneurons, that can be detected either automatically or manually) is between 82 (in control) and 93\% (in APV+NBQX) in head fixed mice, and does not differ between control and KA-treated mice (respectively 76.8 and $79.6 \%$ ). In fact, this quantitative assessment is an underestimate of the actual reliability of postsynaptic fIPSP detection, because the absence of evoked fIPSP in response to the optogenetic stimulation of PV interneurons may also be due to presynaptic factors (e.g. occasional failure to evoke spike firing or GABA release from interneurons stimulated at sub-maximal intensity).

\section{Effects of perisomatic GABAergic events}

Peri-event time histograms display the time-distributions of neuronal activity relative to fIPSPs detected from the same electrode/ shank. The number of spikes was counted within time-bins of $1 \mathrm{~ms}$ around reference events (either fIPSP-peak or optogenetic light-stimulation onset), and normalized by the total number of spikes within the histogram. Baseline activity was computed as the mean (and SD) of values between -50 and $-30 \mathrm{~ms}$. Putative monosynaptic excitatory and inhibitory interactions were assessed from the distribution of action potentials (Csicsvari et al., 1998; Bartho et al., 2004). Pyramidal cells were considered as inhibited by fIPSP-associated events if their firing rate decreased and remained below that of [baseline - 2SD] from 0 to at least $4 \mathrm{~ms}$ after fIPSPpeak. The strength of inhibition was then quantified as the percentage of firing inhibition (relative to baseline) in the inhibitory trough (bin of minimum firing in the $4 \mathrm{~ms}$ post-fIPSPs), and the duration of recovery as the latency to the last of post-fIPSPs time-bin below [baseline - 2SD]. Only cells with [baseline - 2SD] $>0$ were considered to have high and stable enough firing for the possible detection of potential fIPSP-associated inhibition. Pyramidal cells were considered as excited by fIPSP-associated events if their firing rate increased above [baseline $+3 S D$ ] within $4 \mathrm{~ms}$ after fIPSP-peak. Because bursts of action potentials (short interspike intervals) which first spike would evoke a fIPSP would potentially produce a spurious post-fIPSP peak in the peri-event histogram that may be wrongly interpreted as pyramidal cell excitation, we also computed the peri-event histograms of putatively excited pyramidal cells excluding all the spikes preceded by an action potential by less than 10ms. The post-fIPSP peak-firing was still present in all the tested putatively excited pyramidal cells, excluding the contribution of misinterpretation due to burst firing. Pyramidal cells were considered as non-responding if they were neither inhibited nor excited by fIPSP-associated events. In the quantification of the proportion of non-responding pyramidal cells in KA-treated mice, we included only the animals with at least 8 pyramidal neurons with enough spikes for peri-event time histograms (i.e. [baseline - 2SD] > 0).

\section{Theta phase-locking}

The phase histograms illustrated in Figure $6 \mathrm{~B}$ represent the distribution of fIPSPs relative to theta phase. For the determination of theta periods, the raw EEG integrated power was calculated in the $3.5-10 \mathrm{~Hz}$ (theta) and $1-3 \mathrm{~Hz}$ (delta) frequency bands using the multi-taper method (1 s time window and 4 tapers) implemented in the Chronux MATLAB toolbox (Mitra and Bokil, 2008). Theta periods were defined as theta/delta power above 3 and validated manually using the Sonic Visualizer free software. Among the 18 control and $23 \mathrm{KA}$-treated anesthetized mice recorded, only $n=9$ control and $8 \mathrm{KA}$-treated mice expressed reliable theta oscillations, and were thus included in theta-phase modulation analysis. Theta phase was computed in theta periods using the Hilbert transform on the CA3 pyramidale band-pass filtered $(4-11 \mathrm{~Hz})$ LFP (downsampled data, $1250 \mathrm{~Hz}$ ). Phase modulation of fIPSPs relative to 


\section{Cell Reports}

Article

theta oscillations was tested on individual animals by using the Rayleigh test (nonuniformity of the circular distribution). When phase modulation was significant $(p<0.05)$, von Mises parameters $\mu$ and $\kappa$ were estimated via maximum likelihood as indices of preferred phase and modulation strength, respectively (Berens, 2009).

\section{Statistics}

All statistical analyses were performed in MATLAB (MathWorks) or Origin (OriginLab). Statistical details (statistical test used, exact value of $n$ and whether it represents events or animals, etc...) are provided in the main text for each quantified analysis. Data were systematically tested for normal distribution with the Shapiro test. Data following a normal distribution were analyzed using parametric tests (Student's t test or ANOVA and post hoc Bonferroni's test). Data which did not follow a normal distribution were analyzed using nonparametric tests (Mann-Whitney U-test for independent datasets and Wilcoxon signed-ranks test for paired data). Differences were considered statistically significant at $p<0.05$. Unless indicated otherwise, all results are presented as mean \pm SEM. 
Cell Reports, Volume 36

Supplemental information

Probing the polarity of spontaneous perisomatic

GABAergic synaptic transmission

in the mouse CA3 circuit in vivo

Olivier Dubanet, Arnaldo Ferreira Gomes Da Silva, Andreas Frick, Hajime Hirase, Anna Beyeler, and Xavier Leinekugel 
A

ChR2

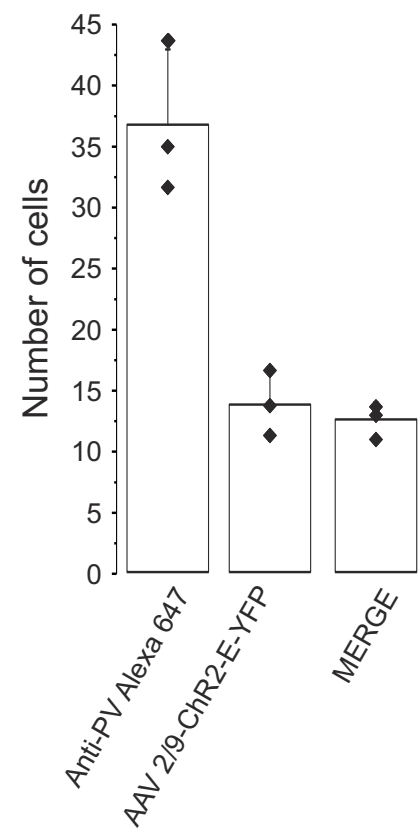

B PSAM-GlyR

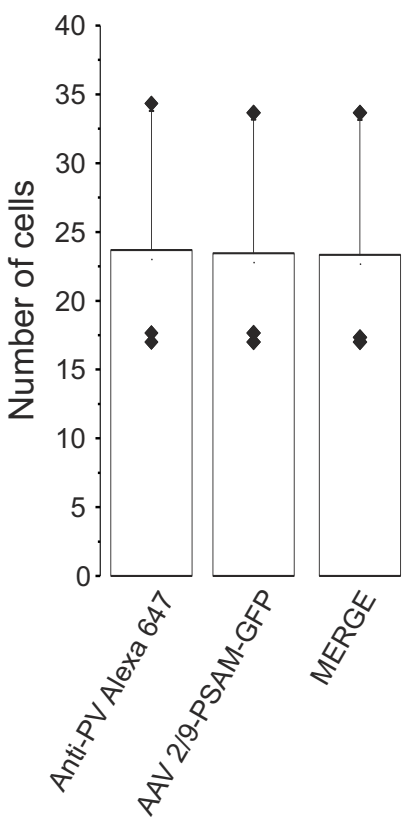

Figure S1: Immuno-histological control of ChR2 and PSAM-GlyR expression in PV interneurons. Related to Figures 2 and 3.

(A) Summary plot (mean $\pm \mathrm{SD}, \mathrm{n}=3$ mice) of the number of cells immuno-positive for PV (anti-PV Alexa 647), for ChR2 E-YFP, or for both (merge). Note that only a fraction of PV cells express ChR2 but that virtually all cells expressing ChR2 are PV cells, indicative of high specificity of ChR2 expression for PV cells.

(B) Summary plot (mean $\pm \mathrm{SD}, \mathrm{n}=3$ mice) of the number of cells immuno-positive for PV (antiPV Alexa 647), for PSAM-GlyR-GFP, or for both (merge). Note that almost all PV cells also express PSAM-GlyR and that virtually all cells expressing PSAM-GlyR are PV cells, indicating high specificity and high coverage of infection for PV cells. 

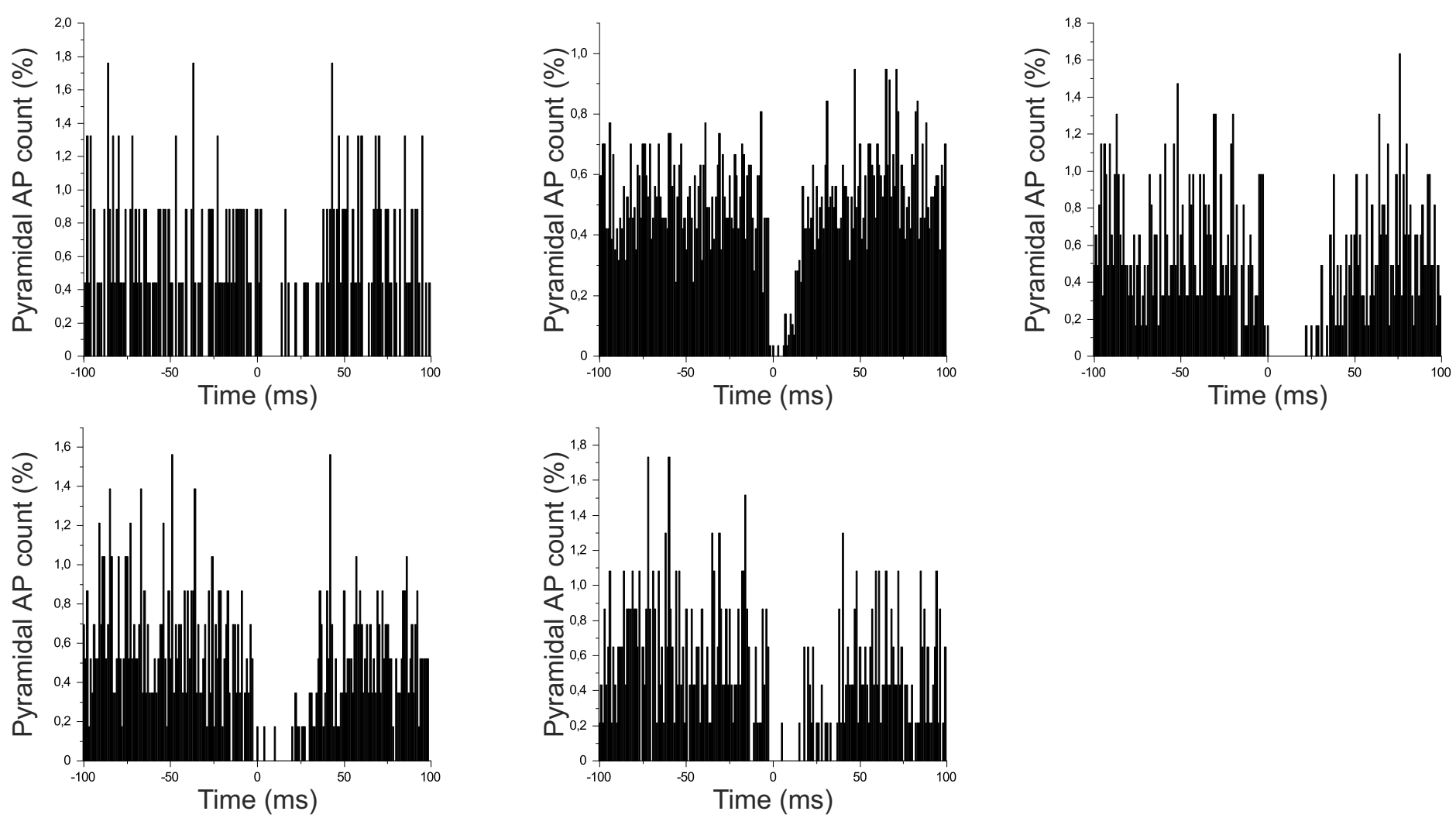

Figure S2: Time-locked inhibition of pyramidal cell firing in response to the optogenetic activation of PVinterneurons. Related to Figure 2.

Peri-event time histograms (time bin $1 \mathrm{~ms}$ ) between all the spikes discharged by putative pyramidal cells and optogenetically evoked fIPSPs (reference) for each individual animal included in Figure $2 \mathrm{f}$ ( $\mathrm{n}=5$ mice). 

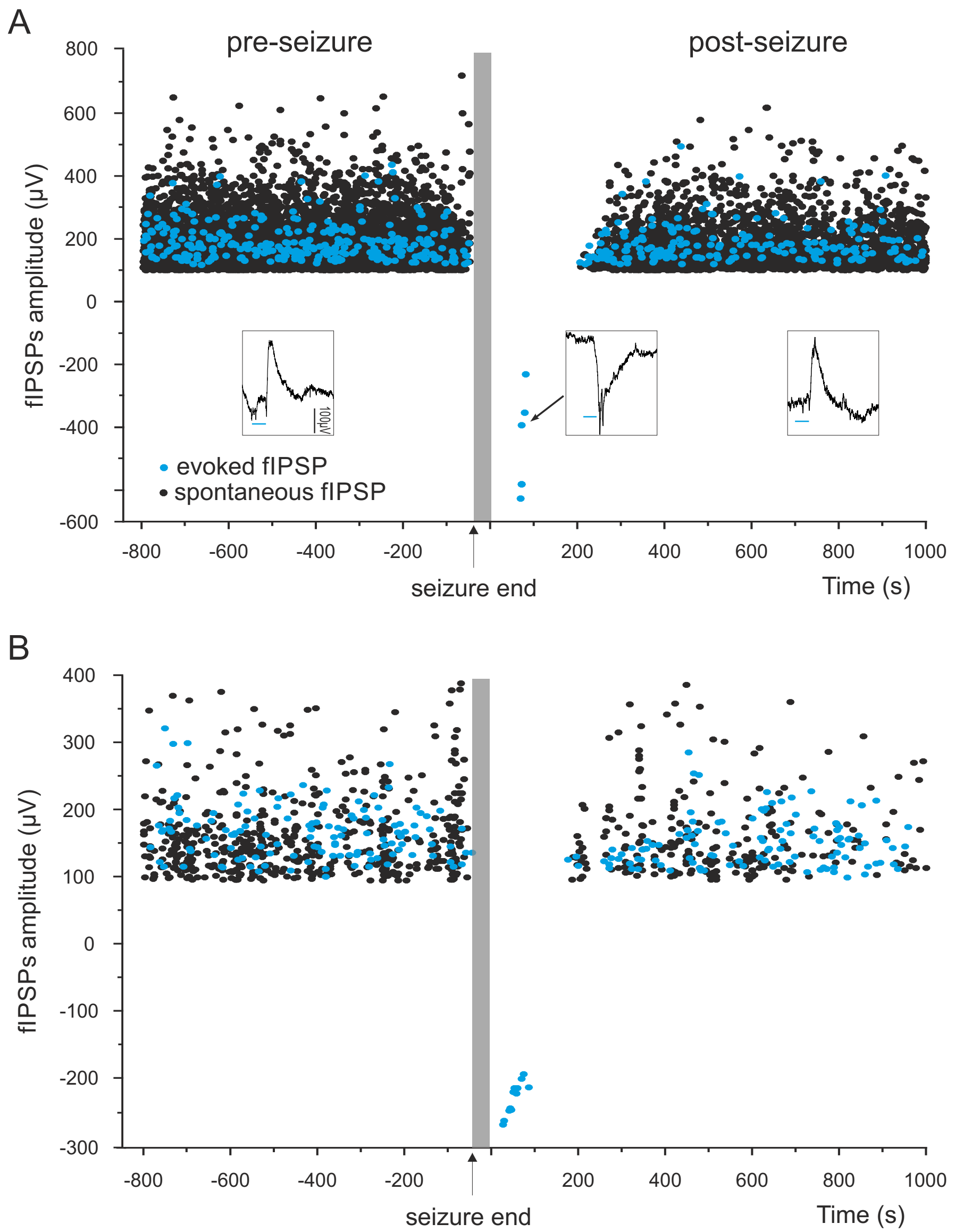

Figure S3: Transiently reversed fIPSPs and perisomatic GABAergic synaptic transmission following acute seizures in individual cases. Related to Figure 4.

(A) Time course of individual fIPSPs amplitude (black dots, spontaneous, blue dots, evoked by optogenetic activation of $\mathrm{PV}$ interneurons, stimulation $2 \mathrm{~ms}$ every $2 \mathrm{~s}$ without interruption throughout the recording), relative to acute seizures induced by the contralateral injection of bicuculline (vertical grey bar, 3 seizures from the same animal, aligned by their ending time). Insets, representative individual field responses (optogenetically evoked fIPSPs; horizontal blue bars, laser ON, vertical scale bar $100 \mu \mathrm{V}$ ) in control (pre-seizure), during the period right after the seizure (reversed polarity), or after recovery (post-seizure). (B) Same as in (A) for a single seizure from another animal. 
Ctr
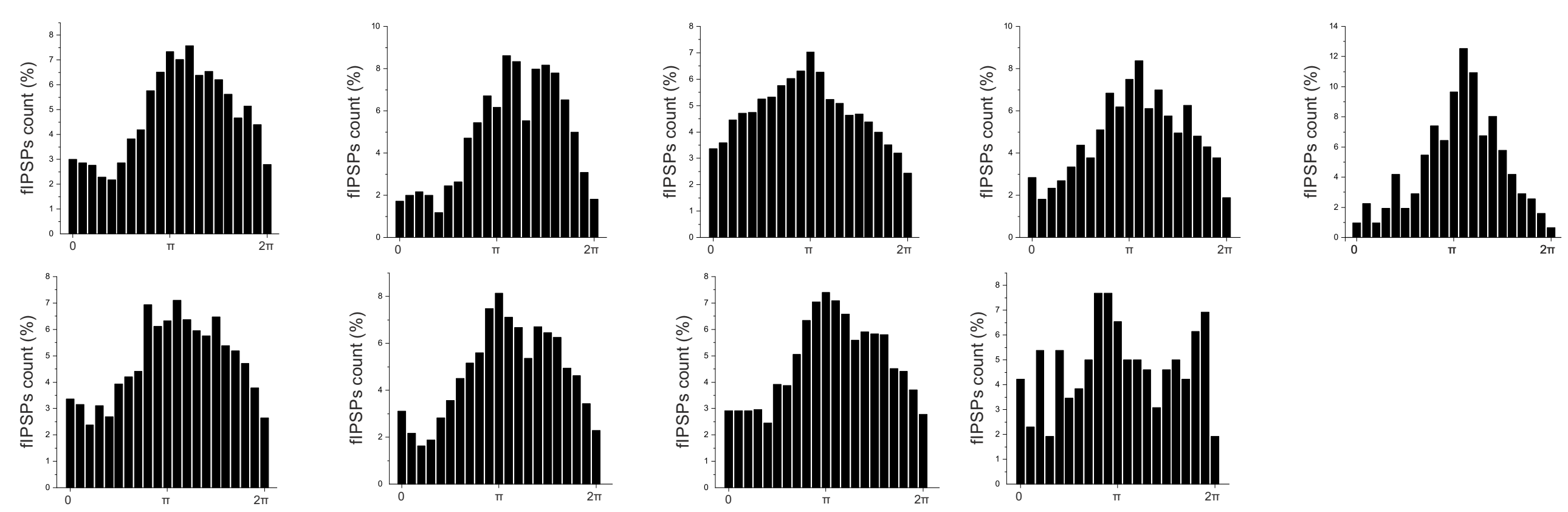

KA
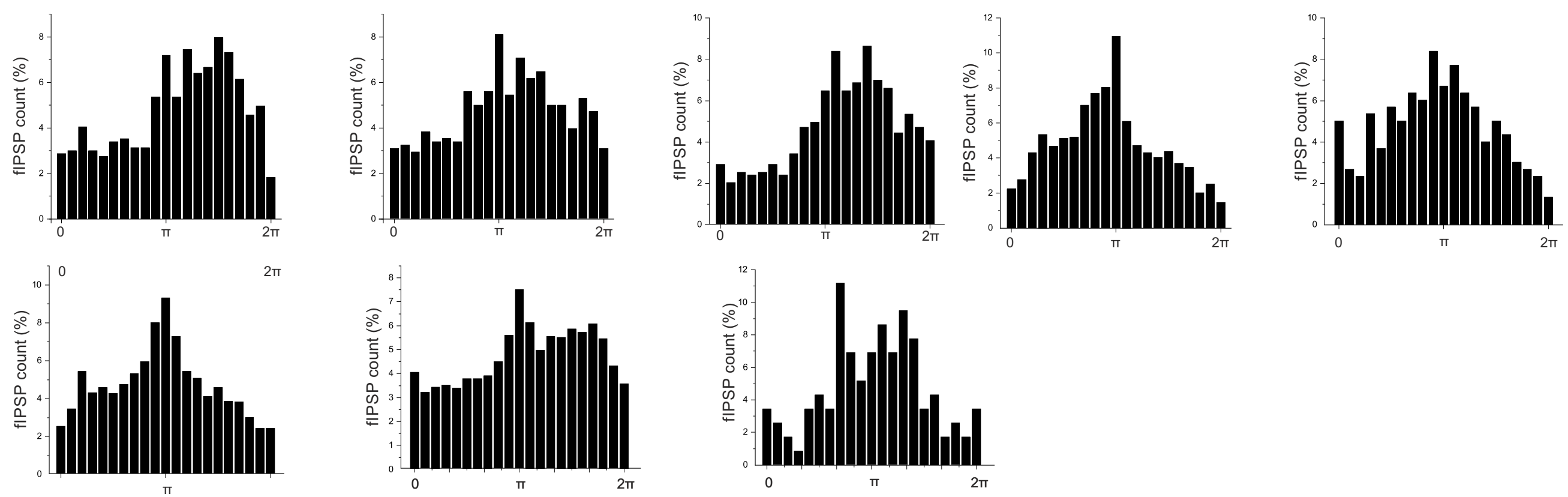

Figure S4: Theta-phase distributions of fI PSPs in control and in KA-teated mice. Related to Figure 6.

Theta-phase distributions of fIPSPs (normalized fIPSP count, \%) for each individual animal of Figure $6 \mathrm{~b}(\mathrm{n}=9$ control mice and 8 KA-treated mice expressing reliable theta oscillations). 

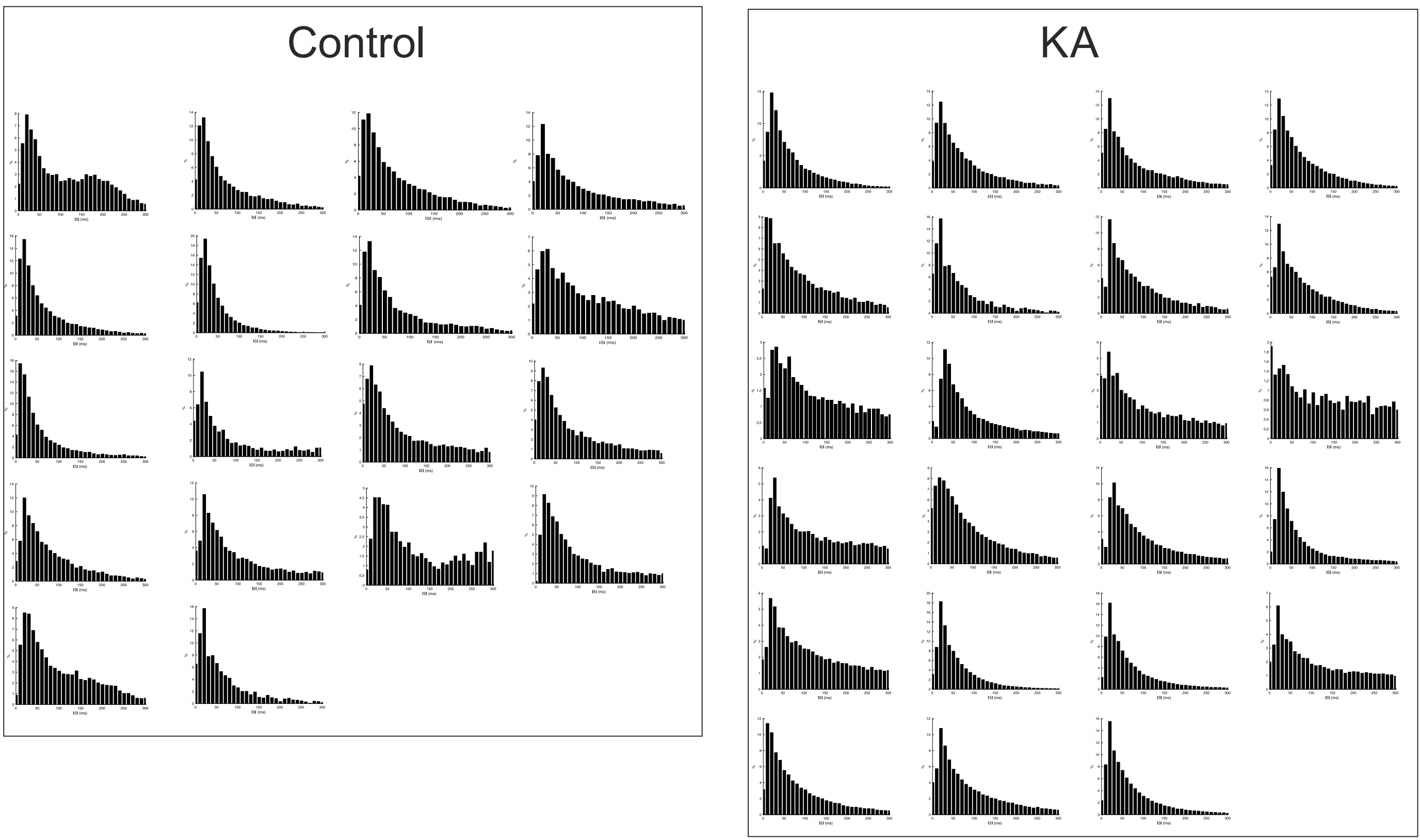

Figure S5: Inter-event (fIPSPs) time interval distributions. Related to Figure 6.

Inter-event (fIPSPs) time interval distributions (normalized fIPSP count, \%), for each anesthetized animal of Figure $6 \mathrm{c}(\mathrm{control}, \mathrm{n}=18 \mathrm{mice}, \mathrm{KA}$-treated, $\mathrm{n}=23 \mathrm{mice})$. 